\title{
Preference of Proteomonas Sulcata Anion Channelrhodopsin for Nitrate Revealed Using a pH Electrode Method
}

\section{Chihiro Kikuchi}

Division of Soft Matter, Graduate School of Life Science, Hokkaido University

\section{Hina Kurane}

Division of Soft Matter, Graduate School of Life Science, Hokkaido University

\section{Takuma Watanabe}

Division of Macromolecular Functions, Department of Biological Science, School of Science, Hokkaido University

\section{Makoto Demura}

Faculty of Advanced Life Science, Hokkaido University

\section{Takashi Kikukawa}

Faculty of Advanced Life Science, Hokkaido University

\section{Takashi Tsukamoto ( $\nabla$ t-tak@sci.hokudai.ac.jp )}

Faculty of Advanced Life Science, Hokkaido University

\section{Research Article}

Keywords: light-gated anion channelrhodopsins (ACRs), ion pump rhodopsins, living organisms

Posted Date: February 1st, 2021

DOl: https://doi.org/10.21203/rs.3.rs-153619/v1

License: (c) (1) This work is licensed under a Creative Commons Attribution 4.0 International License. Read Full License

Version of Record: A version of this preprint was published at Scientific Reports on April 12th, 2021. See the published version at https://doi.org/10.1038/s41598-021-86812-z. 


\section{Preference of Proteomonas sulcata anion channelrhodopsin for nitrate revealed using a pH electrode method}

Chihiro Kikuchi ${ }^{1}$, Hina Kurane ${ }^{1}$, Takuma Watanabe ${ }^{2}$, Makoto Demura ${ }^{3,4}$, Takashi Kikukawa $^{3,4}$ \& Takashi Tsukamoto ${ }^{3,4, *}$

1 Division of Soft Matter, Graduate School of Life Science, Hokkaido University, Sapporo 060-0810, Japan.

2 Division of Macromolecular Functions, Department of Biological Science, School of Science, Hokkaido University, Sapporo 060-0810, Japan.

${ }^{3}$ Faculty of Advanced Life Science, Hokkaido University, Sapporo 060-0810, Japan.

4 Global Station for Soft Matter, Global Institution for Collaborative Research and Education, Hokkaido University, Sapporo 001-0021, Japan.

*Corresponding author: Takashi Tsukamoto

Phone \& Fax: +81 117064475

Email: t-tak@sci.hokudai.ac.jp 


\begin{abstract}
Ion channel proteins are physiologically important molecules in living organisms. Their molecular functions have been investigated using electrophysiological methods, which enable quantitative, precise and advanced measurements and thus require complex instruments and experienced operators. For simpler and easier measurements, we measured the anion transport activity of light-gated anion channelrhodopsins (ACRs) using a pH electrode method, which has already been established for ion pump rhodopsins. Using that method, we successfully measured the anion transport activity and its dependence on the wavelength of light, i.e. its action spectra, and on the anion species, i.e. its selectivity or preference, of several ACRs expressed in yeast cells. In addition, we identified the strong anion transport activity and the preference for $\mathrm{NO}_{3}{ }^{-}$of an $\mathrm{ACR}$ from a marine cryptophyte algae Proteomonas sulcata, named PsuACR 353. Such a preference was discovered for the first time in microbial pump- or channel-type rhodopsins. Nitrate is one of the most stable forms of nitrogen and is used as a nitrogen source by most organisms including plants. Therefore, PsuACR_353 may play a role in $\mathrm{NO}_{3}{ }^{-}$transport and might take part in $\mathrm{NO}_{3}{ }^{-}$-related cellular functions in nature. Measurements of a mutant protein revealed that a Thr residue in the $3^{\text {rd }}$ transmembrane helix, which corresponds to Cys102 in GtACR1, contributed to the preference for $\mathrm{NO}_{3}$ These findings will be helpful to understand the mechanisms of anion transport, selectivity and preference of PsuACR_353.
\end{abstract}




\section{Introduction}

In living cells, there are several kinds of proteins that transport a variety of ions and small molecules across cell membranes. The membrane transport of those substrates is directly or indirectly connected to a variety of life phenomena, such as the maintenance of cell homeostasis, cell signaling, the generation of action potential in neurons, and so on. Therefore, membrane transport proteins are physiologically important and their molecular properties, including their structures and functions, have been intensively investigated by many research groups. In this study, we focused on one type of ion transporter, ion channels.

Ion channels passively transport ions according to the electrochemical potential gradients of ions across cell membranes. No external energy is needed for that type of transport, however some factors, such as membrane potential change, binding of ligands as well as physical or mechanical stimuli, are necessary to open and close those channels. In 2002, the first light-gated ion channel-type microbial rhodopsin for cations (cation channelrhodopsin, abbreviated as CCR) was reported, which originated from a green algae Chlamydomonas reinhardtii and was named channelrhodopsin-1 (abbreviated as ChR1) ${ }^{1}$. As the name suggested, channelrhodopsins belong to a family of microbial rhodopsins, each composed of a seven transmembrane $\alpha$-helical protein opsin and a chromophore all-trans-retinal ${ }^{2}$. A year later, another CCR that originated from the same algae, named channelrhodopsin-2 (abbreviated as ChR2), was reported ${ }^{3}$. ChR1 selectively transports $\mathrm{H}^{+}$, whereas $\mathrm{ChR} 2$ transports not only $\mathrm{H}^{+}$but also other monovalent cations, such as $\mathrm{Li}^{+}, \mathrm{Na}^{+}$and $\mathrm{K}^{+1,3}$. In 2015, natural light-gated anion channelrhodopsins (abbreviated as ACRs) that originated from a cryptophyte algae Guillardia theta, named GtACR1 and GtACR2, were reported ${ }^{4}$. Both of those ACRs are capable of transporting monovalent anions, such as $\mathrm{F}^{-}, \mathrm{Cl}^{-}, \mathrm{Br}^{-}, \mathrm{I}^{-}$and $\mathrm{NO}_{3}{ }^{-4}$. Since then, many more CCRs and ACRs have been identified, characterized and engineered ${ }^{5-25}$. Especially for ACRs, they are novel proteins that have just been discovered and therefore their molecular characteristics and their biological roles remain to be clarified.

The molecular functions of ion channels have been investigated using several experimental techniques. Especially, electrophysiological methods, such as the patchclamp method, are highly quantitative and accurately characterize ion channel functions. In cases of not only ACRs but also CCRs, a series of electrophysiological analyses, such as current-voltage relationship and ion selectivity or preference, have been precisely 
performed. In addition, the introduction of a short-pulsed laser as an actinic light source into the electrophysiological measurement system enables the measurement of transient current changes during a single sequential photochemical reaction of microbial rhodopsins, called the photocycle $2,15,16,19,26,27$. This technique is beneficial for identifying which photo-intermediates facilitate ion conducting and non-conducting states in the photocycle. Therefore, electrophysiological analysis is powerful and necessary to deeply understand the ion channel mechanisms of ACRs and CCRs. However, in exchange for such accuracy, complex instrumental setups and experienced operators are required. This is a bottleneck not only for non-experts in electrophysiology but also for scientists who want to measure ion transport activity more simply and easily.

We conceived the idea to measure the anion transport activity of ACRs using the $\mathrm{pH}$ electrode method, which had already been established for ion pump-type microbial rhodopsins expressed as recombinant proteins in Escherichia coli cells. Simple instrumental setups and usability of the $\mathrm{pH}$ electrode method are a great advantage although the method is less quantitative compared to the electrophysiological method. In addition, the $\mathrm{pH}$ electrode method is expected to easily measure the dependence of the activities of ACRs on the wavelength of excitation light, i.e. action spectra, and on the anion species, i.e. selectivity or preference, even if precise measurements for reversal potentials, current density, kinetics, and so on, are impossible to perform. However, $E$. coli cells cannot be used as host cells to express a variety of recombinant ACRs except for GtACR2 ${ }^{28-30}$. In most cases so far, insect, mammalian and yeast cells have been used as host cells for the expression of recombinant ACRs. Among them, yeast cells are as easy to culture as E. coli cells and to exchange buffers for the measurement of anion transport activity. Therefore, the $\mathrm{pH}$ electrode method is expected to be applicable for ACRs expressed in yeast cells to measure anion transport activity and anion dependence in a relatively simple way.

In this research study, we first developed and demonstrated the feasibility of the $\mathrm{pH}$ electrode method to measure the anion transport activity of ACRs expressed in yeast cells. We used GtACR1, which is a well-studied ACR at present, to test the usefulness of the system. The action spectrum and anion dependence of the activity of GtACR1 measured using the $\mathrm{pH}$ electrode method were almost the same as previously measured using the electrophysiological method ${ }^{4}$. To apply this method to other ACRs, we measured the anion transport activities of 7 ACRs that were successfully expressed in 
yeast cells. As a result, we found that an ACR that originated from a marine cryptophyte algae Proteomonas sulcata, previously named as PsuACR_353 ${ }^{18}$, showed the strongest activity among the ACRs that we tested and preferably transported nitrate $\left(\mathrm{NO}_{3}{ }^{-}\right)$to other monovalent anions, such as $\mathrm{Cl}^{-}$and $\mathrm{Br}^{-}$. $\mathrm{NO}_{3}{ }^{-}$is one of the most stable forms of nitrogen on earth and is used as a nitrogen source by most organisms including plants ${ }^{31}$. Therefore, the light-gated PsuACR_353 may play a role in $\mathrm{NO}_{3}{ }^{-}$transport and might possibly take part in nitrate sensing and signaling, and furthermore, the nitrogen assimilation by $P$. sulcata in nature. Measurement of a mutant protein revealed that the Thr108 residue in the $3^{\text {rd }}$ transmembrane helix, which corresponds to Cys102 in GtACR1, contributed to the $\mathrm{NO}_{3}{ }^{-}$preference in PsuACR_353. These findings will be helpful to understand the mechanisms of anion transport, selectivity and preference of PsuACR_353.

\section{Results}

Concept of the pH electrode method. Fig. 1 illustrates the concept of the $\mathrm{pH}$ electrode method for measuring the anion transport activity of ACRs expressed in yeast cells. The fundamental concept was almost the same as that for the system using E. coli cells. The yeast cell suspension was poured into the glass vial container and the $\mathrm{pH}$ electrode was placed into it. The cell suspension was stirring during the measurement to keep the suspension homogeneous. Continuous LED light $\left(10 \mathrm{~mW} / \mathrm{cm}^{2}\right.$ on average) was illuminated for $2 \mathrm{~min}$ from the side of the vial container. To reduce undesirable artifacts, we were careful not to let the light directly hit the light-sensitive part of the $\mathrm{pH}$ electrode.

Yeast cells have a cell wall outside and a cell membrane inside and ACRs are localized in the cell membrane. Once the light activated ACRs, anions were passively transported into the cells due to the electrochemical potential gradient of anions being higher outside the cells $(300 \mathrm{mM})$ than inside (nearly $0 \mathrm{mM}$ ). This anion influx resulted in making the membrane potential more negative. To compensate for that, protons $\left(\mathrm{H}^{+}\right)$ in the bulk solution penetrate into the cells by passing through the cell wall and cell membrane. As a result, we can indirectly observe anion transport using the $\mathrm{pH}$ electrode as a $\mathrm{pH}$ change of the suspension. In this study, we observed $\mathrm{pH}$ increases that reflect the anion transport into yeast cells. 
Demonstration of the pH electrode method to measure the activity of GtACR1. To ensure that the system works, we used GtACR1 as a test sample. First, we successfully expressed GtACR1 in yeast $P$. pastoris cells according to previous studies ${ }^{27,32}$. We then measured the $\mathrm{Cl}^{-}$transport activity of GtACR1 using the $\mathrm{pH}$ electrode method, and as shown in Fig. 2a, the activity of GtACR1 was successfully measured. The signal for the $\mathrm{pH}$ increase was clearly larger than that of control cells, in which no ACR gene was integrated. In most cases for anion and sodium-ion pump rhodopsins, the measurements were carried out in the presence of a proton-selective ionophore, carbonyl cyanide mchlorophenyl hydrazone (abbreviated as CCCP), which facilitates the proton influx into cells. As a result, the signal of the $\mathrm{pH}$ change becomes larger than that in the absence of CCCP. Conversely, this tendency is evidence for rhodopsins being capable of transporting anions or sodium ions but not protons. However, in the case of GtACR1, the signal intensity of the $\mathrm{pH}$ change was decreased in the presence of CCCP (Fig. 2a) although protons are not transport substrates of GtACR ${ }^{4}$. We concluded that the decrease in signal intensity in the presence of CCCP was caused by the denaturation of GtACR1, which was indicated by the color change of the cell suspension from pink to yellow (Fig. 2b). Therefore, all subsequent measurements were carried out in the absence of CCCP.

We then measured the dependence of the excitation light wavelength on the $\mathrm{Cl}^{-}$ transport activity, i.e. the action spectrum (Fig. 2c). Stronger signals were obtained when the sample was illuminated using $505 \mathrm{~nm}$ and $530 \mathrm{~nm}$ light than by using $590 \mathrm{~nm}$ light. The amplitudes of the initial slope obtained from each condition were averaged and were statistically compared (Fig. 2d). As a result, the activities at $505 \mathrm{~nm}$ and $530 \mathrm{~nm}$ were not significantly different but were stronger than that at $590 \mathrm{~nm}$. This result correlated well with the absorption spectrum of purified GtACR1 (Fig. 2e) and with the action spectrum previously measured using the electrophysiological method ${ }^{4}$. Therefore, the $\mathrm{pH}$ electrode method can be used to investigate the action spectra of ACRs.

The anion-dependent transport activity of GtACR1 was also measured using $530 \mathrm{~nm}$ LED light for activation. Six monovalent anions $\left(\mathrm{F}^{-}, \mathrm{Cl}^{-}, \mathrm{Br}^{-}, \mathrm{I}^{-}, \mathrm{NO}_{3}^{-}\right.$and aspartate (abbreviated as $\left.\mathrm{Asp}^{-}\right)$) and one divalent anion $\left(\mathrm{SO}_{4}{ }^{2-}\right)$ at a concentration of 300 $\mathrm{mM}$ were tested (Figs. $2 \mathrm{f}$ and $2 \mathrm{~g}$ ). As a result, significant transport activities were obtained for the anions except for $\mathrm{F}^{-}$and $\mathrm{Asp}^{-}$compared to the negative control cells. As suggested by a previous electrophysiological study ${ }^{4}$, the anion selectivity of GtACR1 
was not so restricted. Therefore, the $\mathrm{pH}$ electrode method in this study closely reproduced such a dependence. Therefore, we concluded that the $\mathrm{pH}$ electrode method can potentially be applied to measure anion transport activity, the action spectrum and the anion dependence of ACRs expressed in yeast cells.

Application of the pH electrode method to other ACRs. The $\mathrm{pH}$ electrode method was then used to test other ACRs. At present, several ACR genes have been identified by transcriptome analysis. Among them, we tested 8 ACRs (3 from Proteomonas sulcata and 5 from Geminigera cryophila; see Table 1) for functional expression in yeast cells. Five of the 8 ACRs tested in this study belong to the Cys-type (see below) as does GtACR1, 2 belong to the Thr-type as does RapACR reported recently ${ }^{18}$, and 1 belongs to the Val-type as does Gt161302 reported previously ${ }^{4}$. Note that $G$. cryophila has 5 ACRs that belong to all three types.

ACRs can be roughly classified into three types, the Cys-type, the Thr-type and the Val-type (Fig. 3a). One of the factors contributing to that classification is the amino acid conserved at position 102 in GtACR1. It has been reported that two amino acid residues contribute to the channel gating of GtACR $1^{26,27}$. One is Glu68 located in the $2^{\text {nd }}$ transmembrane helix that controls slow-opening/fast-closing gates (Table 1 and Supplementary Fig. S1). Another is Cys102 located in the $3^{\text {rd }}$ transmembrane helix that regulates fast-opening/slow-closing gates. The Glu residue is completely conserved in all ACRs we tested, whereas the Cys residue is substituted with Thr or Val (Table 1, Fig. 3a, and Supplementary Fig. S1). For the case of the recently reported RapACR, the Thr residue corresponding to Cys102 in GtACR1 was also shown to contribute to the channel gating kinetics ${ }^{18}$. However, the effect of such diversity in the amino acid conservation on anion transport activity, anion selectivity or preference is not well understood. No anion transport activity was reported for Gt161302, which has a Val residue corresponding to Cys102 in GtACR $1^{4}$.

As shown in Fig. 3b, 7 of the 8 ACRs, except GcACR_439, were pigmented in the presence of all-trans-retinal, indicating their successful expression in yeast cells. We then measured the $\mathrm{Cl}^{-}$transport activities for these ACRs using the $\mathrm{pH}$ electrode method. For activation, $505 \mathrm{~nm}$ LED light was used for ZipACR, GcACR_145 and GcACR_457, while $530 \mathrm{~nm}$ LED light was used for PsuACR1, PsuACR_353, GcACR_197 and GcACR_201, by taking into account the colors of the cells and the action spectral maxima 
reported previously ${ }^{15-18}$. The intensity of light was kept at an average of $10 \mathrm{~mW} / \mathrm{cm}^{2}$. As a result, the signals of $\mathrm{pH}$ change were obtained in most ACRs but the intensities were very weak (Fig. 3c). However, only PsuACR_353 generated a strong signal of a pH increase, indicating its significant $\mathrm{Cl}^{-}$transport activity compared to the other ACRs.

Characterization of the anion transport activity of PsuACR_353. To characterize the anion transport activity of PsuACR_353, we measured the action spectrum and anion dependence of its transport activity using the $\mathrm{pH}$ electrode method. Fig. 4a shows that the $\mathrm{Cl}^{-}$transport activities of PsuACR_353 depend on the excitation light wavelength. Statistical comparisons of the initial slope amplitudes revealed that the activity at $530 \mathrm{~nm}$ was significantly larger than that at $590 \mathrm{~nm}$ (Fig. 4b). This result correlated well with a previous electrophysiological study ${ }^{18}$. We then measured the anion dependence of the transport activity of PsuACR_353 using $530 \mathrm{~nm}$ light. Strong signals were observed not only for $\mathrm{Cl}^{-}$but also for $\mathrm{Br}^{-}, \mathrm{I}^{-}, \mathrm{NO}_{3}{ }^{-}$and even $\mathrm{SO}_{4}{ }^{2-}$ despite the low level of expression (Figs. $4 \mathrm{c}, 3 \mathrm{~b}$ and $5 \mathrm{~b}$ explained below). Especially for $\mathrm{NO}_{3}{ }^{-}$, the $\mathrm{pH}$ was increased by nearly 0.15 unit, which is ca. 3-times larger than even for the $\mathrm{Cl}^{-}$transport of GtACR1 (Fig. 2f). In addition, statistical analysis clearly showed the strongest activity for $\mathrm{NO}_{3}{ }^{-}$, which was more than 2-times larger than that for the other anions (Fig. 4d). These results indicated that the anion selectivity of PsuACR_353 was not restricted as was GtACR1 (Fig. 2g), however PsuACR_353 preferably transported $\mathrm{NO}_{3}{ }^{-}$.

To quantitatively compare the anion transport activities of GtACR1 and PsuACR_353, their expression levels were estimated by Western blotting (Figs. 5a and 5b). The results showed that the relative level of expression of PsuACR_353 was ca. 0.46-times smaller than that of GtACR1. Fig. 5c and Supplementary Fig. S2 show statistical comparisons of the anion transport activities after correction to account for the expression levels of GtACR1 and PsuACR_353. These results clearly showed that the transport activities of PsuACR_353 for $\mathrm{Cl}^{-}$and $\mathrm{NO}_{3}{ }^{-}$were ca. 2- and 5-times larger than that for GtACR1, respectively, and therefore the preference for $\mathrm{NO}_{3}{ }^{-}$of $P s u A C R \_353$ was far greater than GtACR1 and other anion species.

\section{Anion transport activities of GtACR1-C102T and PsuACR_353-T108C mutants.} Finally, the anion transport activities of mutant ACRs were investigated using the $\mathrm{pH}$ electrode method. As described in the previous section, one difference in the amino acid 
sequence between GtACR1 and PsuACR_353 is the amino acid conserved in the $3^{\text {rd }}$ transmembrane helix, i.e. GtACR1 has Cys102 whereas PsuACR_353 has Thr108 at that position (Table 1, Figs. 3a, 6a, and Supplementary Fig. S1). We investigated the effects of that difference on anion transport activity, anion selectivity and preference of GtACR1C102T and PsuACR_353-T108C mutants using the pH electrode method.

For the GtACR1-C102T mutant (Figs. 6b and 6c), the intensities of the $\mathrm{pH}$ change and initial slope increased compared to wild-type GtACR1 (Figs. 2f and 2g). However, the anion dependence was almost the same as the wild-type (Figs. 6c and 2g). The expression level of the GtACR1-C102T mutant was also not significantly different from the wild-type (Figs. 5a and 5b). Taking this into account, a statistical comparison showed that the transport activities of anions other than $\mathrm{F}^{-}$were almost the same as those of the wild-type (Fig. 5c and Supplementary Fig. S2). On the other hand, when compared with the transport activities of wild-type PsuACR_353, the transport activities of the GtACR1-C102T mutant were significantly smaller and the preference for $\mathrm{NO}_{3}{ }^{-}$was only slightly enhanced (Fig. 5c and Supplementary Fig. S2). Therefore, the Cys-to-Thr mutation at position 102 in GtACR1 resulted in almost no effect either on the anion transport activity or the selectivity or preference.

However, for the PsuACR_353-T108C mutant (Figs. 6d and 6e), decreases in transport activities were observed for all anions by compared with wild-type PsuACR_353 (Figs. 4c and 4d). In addition, the intensities of $\mathrm{pH}$ changes and initial slopes resulted in decreases to almost the same level (Figs. 6d and 6e), indicating that the anion dependence was completely lost due to that mutation. Taking into account the expression level of the PsuACR_353-T108C mutant, which was about 7-times larger than wild-type GtACR1 (Figs. 5a and 5b), we concluded that the Thr-to-Cys mutation at position 108 in PsuACR_353 caused a significant loss of function (Fig. 5c and Supplementary Fig. S2). These results indicate that the effects of the corresponding amino acids at positions 102 in GtACR1 and 108 in PsuACR_353 on anion transport activity were completely different from each other, which would reflect the phylogenetic difference (Fig. 3a). 


\section{Discussion}

In this study, we used the $\mathrm{pH}$ electrode method to measure the anion transport activity of ACRs expressed as recombinant proteins in yeast cells. That method has already been established and used for ion pump-type microbial rhodopsins expressed in E. coli cells. Therefore, this is the first study that measured the activity of ion channel-type rhodopsins expressed in yeast cells. The advantages of this method include the simple instrumental setup and the use of a glass electrode $\mathrm{pH}$ meter, and the ease of measurement even for non-experts in electrophysiology. Indeed, electrophysiological techniques are powerful and are required for quantitative and precise measurements of ion channel functions. However, as we demonstrate here, the action spectrum and the substrate dependence of anion transport activity can be easily measured using the $\mathrm{pH}$ electrode method. We assume that this method will also be useful as a screening technique to explore and engineer ACRs with unique absorptions, anion selectivities, and so on.

We newly characterize the strong anion transport activity and $\mathrm{NO}_{3}{ }^{-}$preference of PsuACR_353 in this study. Govorunova et al. already performed electrophysiological measurements for various ACRs including PsuACR_353 ${ }^{18}$. However, no results were reported for such preferences probably because they did not perform the electrophysiological measurements using various anions other than $\mathrm{Cl}^{-}$. One reason for that we suppose is that the light-induced current of PsuACR_353 caused by $\mathrm{Cl}^{-}$transport was significantly smaller than not only the other ACRs tested but also for GtACR1 ${ }^{4,18}$. That may be due to the much lower expression levels of PsuACR_353 in their mammalian cell expression system because its expression level was also significantly small even in our yeast expression system (Figs. 5a and 5b). We noticed that the magnitude relationship of the $\mathrm{Cl}^{-}$transport activities of PsuACR_353 and GtACR1 reported by Govorunova et al. ${ }^{4,18}$ were completely different from our results obtained using the $\mathrm{pH}$ electrode method (Fig. 5c). This may also reflect differences in the expression levels of GtACR1 and PsuACR_353 in each protein expression system.

On the other hand, the anion-dependent transport activity determined by each method can be considered equivalent. In the first report of GtACR1, its anion dependence was revealed by an electrophysiological method ${ }^{4}$. The result was that GtACR1 transported $\mathrm{Cl}^{-}, \mathrm{Br}^{-}, \mathrm{I}^{-}$and $\mathrm{NO}_{3}{ }^{-}$almost equally but transported $\mathrm{F}^{-}$more weakly. In this study, we were successfully reproduced such a dependence using the $\mathrm{pH}$ electrode method (Fig. 2g). The anion selectivity of GtACR1 is not restricted, which is similar to 
the anion pump rhodopsins but different from the potassium channel. It is speculated that a structure or a mechanism working as an anion selective filter is not necessarily sophisticated in GtACR1. Conversely, such an unrestricted anion selectivity may be connected to its biological roles in the algae $G$. theta, which awaits clarification in further studies. In contrast, PsuACR_353 was revealed to transport $\mathrm{NO}_{3}{ }^{-}$preferably to the other anions tested in this study (Figs. 4c, 4d, 5c and Supplementary Fig. S2). In the sense that PsuACR_353 transported $\mathrm{Cl}^{-}, \mathrm{Br}^{-}$and $\mathrm{I}^{-}$almost equally, which was the same as GtACR1, and even $\mathrm{SO}_{4}{ }^{2-}$, the anion selectivity was not restricted. However, the preference for $\mathrm{NO}_{3}{ }^{-}$ was far greater than the other anions. To our knowledge, such a preference has not been discovered in any microbial pump- or channel-type rhodopsins reported so far.

Nitrate $\left(\mathrm{NO}_{3}{ }^{-}\right)$is one of the most stable forms of nitrogen on earth and is used as a nitrogen source by most organisms including plants ${ }^{31}$. For $\mathrm{NO}_{3}{ }^{-}$transport, both pump- and channel-type transporters exist in nature. Among them, a slowly activating anion channel 1 named SLAC1 and its homologous proteins named SLAH2 and SLAH3 expressed in plants are known to transport $\mathrm{NO}_{3}{ }^{-}$preferably and take part in nitrate acquisition in roots, in nitrate translocation from roots to shoots, and in guard cell closure 31,34. Therefore, PsuACR_353 may play a role in $\mathrm{NO}_{3}{ }^{-}$transport and might possibly take part in nitrate sensing and signaling, and furthermore, in the nitrogen assimilation in $P$. sulcata in nature. Indeed, it is known that P. sulcata senses the concentration of nitrate outside the cell and accumulates nitrogen as a form of protein-pigment, phycoerythrin, which contributes to the light-harvesting function for photosynthesis ${ }^{35,36}$. It should be noted that we tried to purify PsuACR_353 to more deeply understand the mechanism and role of $\mathrm{NO}_{3}{ }^{-}$transport using spectroscopic techniques, but those efforts failed because the protein was unstable in the presence of a detergent.

We wonder why PsuACR_353 is able to preferably transport $\mathrm{NO}_{3}{ }^{-}$. One possible explanation is that the ionic radii or hydrated radii of anions contribute to the preference ${ }^{37}$. However, no sequential correlation is seen because the ionic and hydrated radii of $\mathrm{NO}_{3}{ }^{-}$are $0.177 \mathrm{~nm}$ and $0.316 \mathrm{~nm}$ (Table 2), respectively, which is almost the same as those of $\mathrm{Cl}^{-}(0.180 \mathrm{~nm}$ and $0.319 \mathrm{~nm}$, respectively). The crystallographic structure of GtACR1 in the dark state revealed that there is a continuous tunnel spanning through the protein, which is constructed by the $1^{\text {st }}-3^{\text {rd }}$, and $7^{\text {th }}$ transmembrane helices (Supplementary Fig. S1), and the radius of that tunnel is the same or smaller than the ionic radius of $\mathrm{Cl}^{-}(0.1-0.2 \mathrm{~nm})^{38,39}$. More recently, it was revealed that the tunnel radius 
is variable according to the anion species to be transported by GtACR $1{ }^{40}$. Of course, a transient change of the tunnel radius accompanied by a structural change of the protein should also be considered because the structures of GtACR1 represent the state before light activation ${ }^{38-40}$, and the unrestricted anion selectivity of GtACR1 can be explained by the size of the tunnel radius and the ionic radius of anions. Another possible explanation is that when PsuACR_353 transports $\mathrm{NO}_{3}{ }^{-}$upon light activation, some spaces or sites are transiently formed, where $\mathrm{NO}_{3}{ }^{-}$is preferably trapped or passes through, during the photocycle. Among the anions we tested in this study, only $\mathrm{NO}_{3}{ }^{-}$is not spherically symmetrical. Thus, $\mathrm{NO}_{3}{ }^{-}$has two hydrated radii, one for the axial radius and another for the equatorial radius (Table 2) ${ }^{37}$. Therefore, it is speculated that a possible mechanism for the $\mathrm{NO}_{3}{ }^{-}$preference is that $P s u A C R \_353$ transiently recognizes the asymmetrical structure of $\mathrm{NO}_{3}{ }^{-}$and therefore transports $\mathrm{NO}_{3}{ }^{-}$being hydrated.

We suppose that Thr108 in PsuACR_353 is one of the residues contributing to the $\mathrm{NO}_{3}^{-}$preference, which is based on comparisons of PsuACR_353-T108C and GtACR1-C102T mutants (Figs. 5c, 6, and Supplementary Fig. S2). We investigated the effects of differences in amino acid residues at positions 102 and 108 in GtACR1 and in PsuACR_353, respectively, on their anion transport activities, anion selectivity or preference for the first time in this study. Because the phylogenetic relationship between these ACRs is distant from each other (Fig. 3a), it is conceivable that the anion conducting paths and mechanisms in each ACR are different. The crystal structure of GtACR1 suggested that Cys 102 is not involved in the anion conducting path ${ }^{38-40}$. On the other hand, in PsuACR_353, Thr108 may be a part of a conducting path dedicated for $\mathrm{NO}_{3}{ }^{-}$.

Conclusion. In this study, we successfully demonstrated the usefulness of the $\mathrm{pH}$ electrode method to measure the anion transport activity of ACRs. This method allows us to measure the action spectra and the anion dependence of the transport activity simply and easily, with results comparable to previous results obtained using electrophysiological methods. In addition, we identified the strong anion transport activity and the preference for $\mathrm{NO}_{3}{ }^{-}$in $P s u A C R \_353$ for the first time. Nitrate is one of the most stable forms of nitrogen and is used as a nitrogen source by most organisms including plants. Therefore, PsuACR_353 may play a role in $\mathrm{NO}_{3}{ }^{-}$transport and might take part in $\mathrm{NO}_{3}{ }^{-}$-related cellular functions in nature. Furthermore, we successfully 
demonstrated that Thr108, which corresponds to Cys102 in GtACR1, contributes to the $\mathrm{NO}_{3}{ }^{-}$preference of PsuACR_353. Such a preference has been discovered for the first time in microbial pump- or channel-type rhodopsins. This finding will be helpful to understand the anion transport mechanism of PsuACR_353. We did not address the potential use of $\mathrm{NO}_{3}{ }^{-}$-preferred PsuACR_353 for optogenetics because $\mathrm{NO}_{3}{ }^{-}$is rare in mammalian cells. Possibly, PsuACR_353 may be useful for optogenetics in plants.

\section{Methods}

DNA constructs of ACRs. Gene information about ACRs used in this study was obtained from GenBank and is summarized in Table 1. An 8 histidine tag was attached to the Cterminus of each ACR. The genes encoding ACRs with codon optimization for expression in Pichia pastoris were purchased from GENEWIZ (South Plainfield, NJ, U.S.A.). The procedures for constructing the pPICZ B vector (Thermo Fisher Scientific, Waltham, MA, U.S.A.) for P. pastoris were the same as our previous report ${ }^{32}$. The genes for GtACR1C102T and PsuACR_353-T108C mutants were prepared using PrimeSTAR Max DNA Polymerase (Takara Bio Inc., Shiga, Japan). The correctness of all nucleotide sequences was verified by dideoxy sequencing.

Protein expression. The methylotrophic yeast Pichia pastoris SMD1168H strain (Thermo Fischer Scientific) was used as the protein expression host. The procedures for transformation of yeast and for the protein expression were almost the same as our previous report ${ }^{32}$. Briefly, transformed $P$. pastoris SMD1168H cells were pre-cultured in BMGY medium containing $100 \mu \mathrm{g} / \mathrm{mL}$ Zeocin ${ }^{\mathrm{TM}}$ (Thermo Fisher Scientific) for 1 day at $30^{\circ} \mathrm{C}$. The medium was exchanged to BMMY containing $100 \mu \mathrm{g} / \mathrm{mL}$ Zeocin $^{\mathrm{TM}}, 2 \%$ (v/v) methanol (Fuji Film Wako Chemical Industries, Co. Ltd., Japan) and $20 \mu \mathrm{M}$ alltrans-retinal (Sigma-Aldrich, St. Louis, MO, U.S.A.), and protein expression was induced for 1 day at $30^{\circ} \mathrm{C}$. The cells were collected by centrifugation $(3,000 \mathrm{rpm}, 5 \mathrm{~min}$, $4{ }^{\circ} \mathrm{C}$; himac CF16RN equipped with a T9A31 rotor; Hitachi Koki Co., Ltd., Tokyo, Japan).

Anion transport activity measurement and data analysis. To measure anion transport activity, P. pastoris SMD1168H cells expressing ACRs were washed with $300 \mathrm{mM}$ salt solution $\left(\mathrm{NaCl}, \mathrm{NaF}, \mathrm{NaBr}, \mathrm{NaI}, \mathrm{NaNO}_{3}, \mathrm{Na}_{2} \mathrm{SO}_{4}\right.$, sodium aspartate; all from Fuji Film 
Wako Chemical Industries) 4 times by centrifugation $\left(3,000 \mathrm{rpm}, 5 \mathrm{~min}, 4^{\circ} \mathrm{C}\right.$; himac CF16RN equipped with a T9A31 rotor). The cells were finally suspended in the same salt solution used for washing. As a negative control, P. pastoris SMD1168H cells without integration of any ACR gene were prepared. The optical density at $660 \mathrm{~nm}$ of each cell suspension was measured using a UV-1800 spectrophotometer (Shimadzu Corp., Kyoto, Japan) and adjusted to 1.9 on average. Anion transport activity was measured at temperatures below room temperature $\left(16^{\circ} \mathrm{C}\right.$ on average $)$ by monitoring $\mathrm{pH}$ changes using a LAQUA F-72 pH meter equipped with a standard ToupH pH electrode (HORIBA, Ltd., Kyoto, Japan). To measure the dependence of transport activity on the wavelength of light, blue-green (peak wavelength is $505 \mathrm{~nm}$ ), green (peak wavelength is $530 \mathrm{~nm}$ ) and orange (peak wavelength is $590 \mathrm{~nm}$ ) LED light was illuminated. The light intensity was adjusted to $10 \mathrm{~mW} / \mathrm{cm}^{2}$ on average, which was measured using a power meter (ORION, Ophir Optronics Solutions Ltd., Jerusalem, Israel). Anion transport activity was estimated by the initial slope of the first $10 \mathrm{sec}$ after LED light illumination for the time-dependent $\mathrm{pH}$ changes. More than three independent measurements were averaged. For statistical analysis, one-way ANOVA followed by Dunnett's test and Tukey's test were performed using GraphPad Prism 9 software (GraphPad Software, San Diego, CA, U.S.A.).

SDS-PAGE and Western blotting. SDS-PAGE with $12 \%(\mathrm{v} / \mathrm{v})$ polyacrylamide gels and Western blotting using an anti-His tag antibody conjugated with horseradish peroxidase (anti-His-tag mAb-HRP-DirecT, MBL Co., Ltd., Nagoya, Japan) were performed using standard protocols. $P$. pastoris cell samples were prepared as previously published ${ }^{33}$. Briefly, $1 \mathrm{~mL}$ of each cell suspension at an $\mathrm{OD}_{660}$ of ca. 1.9 was centrifuged to collect cell pellets. The wet weight of the cell pellets was $10 \mathrm{mg}$ on average. The cell pellets were then resuspended in $1 \mathrm{~mL} 0.1 \mathrm{M} \mathrm{NaOH}$ and incubated for 5 min at room temperature. After centrifugation to remove the supernatant, the cell pellets were suspended in $250 \mu \mathrm{L}$ SDS-PAGE sample buffer (60 mM Tris- $\mathrm{HCl}$ (pH 6.8), 2\% (w/v) SDS, 5\% (v/v) glycerol, $4 \%(\mathrm{v} / \mathrm{v}) \beta$-mercaptoethanol and $0.0025 \%(\mathrm{w} / \mathrm{v})$ bromophenol blue) and then boiled at $95^{\circ} \mathrm{C}$ for 5 min. Finally, after centrifugation again, $6 \mu \mathrm{L}$ of each supernatant diluted by one-sixth was loaded on the gel. To estimate the total amount of each ACR expressed in $P$. pastoris cells, the band intensities were analyzed using ImageJ software (U.S. National Institutes of Health, Bethesda, MD, U.S.A.) and 5 independent measurements were 
averaged. For statistical analysis, one-way ANOVA followed by Dunnett's test was performed using GraphPad Prism 9 software (GraphPad Software).

\section{Acknowledgements}

This research was supported by grants from the Japan Society for the Promotion of Science (Grant-in-Aid for Young Scientists, No. 18K1465808), from Hokkaido University Tenure Track System, and from Global Station for Soft Matter, a project of Global Institution for Collaborative Research and Education at Hokkaido University. The authors thank DASS Manuscript for English language editing.

\section{Author contributions}

T.T. designed the research. C.K., H.K., T.W. and T.T. performed experiments and analyzed data. M.D. and T.K. provided technical assistance. C.K. and T.T. wrote the paper. All authors discussed and confirmed the results of the paper.

\section{Notes}

The authors declare no competing financial interest.

\section{References}

1. Nagel, G. et al. Channelrhodopsin-1: a light-gated proton channel in green algae. Science 296, 2395-2398 (2002).

2. Ernst, O. P. et al. Microbial and animal rhodopsins: structures, functions, and molecular mechanisms. Chem. Rev. 114, 126-163 (2014).

3. Nagel, G. et al. Channelrhodopsin-2, a directly light-gated cation-selective membrane channel. Proc Natl Acad Sci USA 100, 13940-13945 (2003).

4. Govorunova, E. G., Sineshchekov, O. A., Janz, R., Liu, X. \& Spudich, J. L. Natural light-gated anion channels: A family of microbial rhodopsins for advanced optogenetics. Science 349, 647-650 (2015).

5. Sineshchekov, O. A., Jung, K.-H. \& Spudich, J. L. Two rhodopsins mediate 
phototaxis to low- and high-intensity light in Chlamydomonas reinhardtii. Proc Natl Acad Sci USA 99, 8689-8694 (2002).

6. Suzuki, T. et al. Archaeal-type rhodopsins in Chlamydomonas: model structure and intracellular localization. Biochem Biophys Res Commun 301, 711-717 (2003).

7. $\quad$ Ernst, O. P. et al. Photoactivation of channelrhodopsin. J. Biol. Chem. 283, 16371643 (2008).

8. Kianianmomeni, A., Stehfest, K., Nematollahi, G., Hegemann, P. \& Hallmann, A. Channelrhodopsins of Volvox carteri are photochromic proteins that are specifically expressed in somatic cells under control of light, temperature, and the sex inducer. Plant Physiol 151, 347-366 (2009).

9. Zhang, F. et al. Red-shifted optogenetic excitation: a tool for fast neural control derived from Volvox carteri. Nat. Neurosci. 11, 631-633 (2008).

10. Govorunova, E. G., Sineshchekov, O. A., Li, H., Janz, R. \& Spudich, J. L. Characterization of a Highly Efficient Blue-shifted Channelrhodopsin from the Marine Alga Platymonas subcordiformis. J. Biol. Chem. 288, 29911-29922 (2013).

11. Govorunova, E. G., Spudich, E. N., Lane, C. E., Sineshchekov, O. A. \& Spudich, J. L. New channelrhodopsin with a red-shifted spectrum and rapid kinetics from Mesostigma viride. MBio 2, e00115-11 (2011).

12. Hou, S.-Y. et al. Diversity of Chlamydomonas channelrhodopsins. Photochem Photobiol 88, 119-128 (2012).

13. Zhang, F. et al. The microbial opsin family of optogenetic tools. Cell 147, 14461457 (2011).

14. Klapoetke, N. C. et al. Independent optical excitation of distinct neural populations. Nat. Methods 11, 338-346 (2014).

15. Govorunova, E. G., Sineshchekov, O. A. \& Spudich, J. L. Proteomonas sulcata ACR1: A Fast Anion Channelrhodopsin. Photochem Photobiol 92, 257-263 (2016).

16. Wietek, J., Broser, M., Krause, B. S. \& Hegemann, P. Identification of a Natural Green Light Absorbing Chloride Conducting Channelrhodopsin from Proteomonas sulcata. J. Biol. Chem. 291, 4121-4127 (2016).

17. Govorunova, E. G. et al. The Expanding Family of Natural Anion Channelrhodopsins Reveals Large Variations in Kinetics, Conductance, and Spectral Sensitivity. Sci. Rep. 7, 43358 (2017). 
18. Govorunova, E. G. et al. Extending the Time Domain of Neuronal Silencing with Cryptophyte Anion Channelrhodopsins. eNeuro 5, e0174-18 (2018).

19. Oppermann, J. et al. MerMAIDs: a family of metagenomically discovered marine anion-conducting and intensely desensitizing channelrhodopsins. Nat Commun 10, 3315-13 (2019).

20. Wietek, J. et al. Anion-conducting channelrhodopsins with tuned spectra and modified kinetics engineered for optogenetic manipulation of behavior. Sci. Rep. 7, 14957 (2017).

21. Rozenberg, A. et al. Lateral Gene Transfer of Anion-Conducting Channelrhodopsins between Green Algae and Giant Viruses. Curr. Biol. 30, 49104920.e5 (2020).

22. Wietek, J. et al. Conversion of Channelrhodopsin into a Light-Gated Chloride Channel. Science 344, 409-412 (2014).

23. Berndt, A., Lee, S. Y., Ramakrishnan, C. \& Deisseroth, K. Structure-Guided Transformation of Channelrhodopsin into a Light-Activated Chloride Channel. Science 344, 420-424 (2014).

24. Schneider, F., Grimm, C. \& Hegemann, P. Biophysics of Channelrhodopsin. Annu. Rev. Biophys. 44, 167-186 (2015).

25. Kato, H. E. et al. Structural mechanisms of selectivity and gating in anion channelrhodopsins. Nature 561, 349-354 (2018).

26. Sineshchekov, O. A., Govorunova, E. G., Li, H. \& Spudich, J. L. Gating mechanisms of a natural anion channelrhodopsin. Proc Natl Acad Sci USA 112, 14236-14241 (2015).

27. Sineshchekov, O. A., Li, H., Govorunova, E. G. \& Spudich, J. L. Photochemical reaction cycle transitions during anion channelrhodopsin gating. Proc Natl Acad Sci USA 113, E1993-E2000 (2016).

28. Doi, S., Tsukamoto, T., Yoshizawa, S. \& Sudo, Y. An inhibitory role of Arg-84 in anion channelrhodopsin-2 expressed in Escherichia coli. Sci. Rep. 7, 41879 (2017).

29. Kojima, K. et al. Mutational analysis of the conserved carboxylates of anion channelrhodopsin-2 (ACR2) expressed in Escherichia coli and their roles in anion transport. Biophys Physicobiol 15, 179-188 (2018).

30. Kojima, K. et al. Green-Sensitive, Long-Lived, Step-Functional Anion Channelrhodopsin-2 Variant as a High-Potential Neural Silencing Tool. J. Phys. 
Chem. Lett. 11, 6214-6218 (2020).

31. Vidal, E. A. et al. Nitrate in 2020: Thirty Years from Transport to Signaling Networks. Plant Cell 32, 2094-2119 (2020).

32. Tsukamoto, T. et al. Implications for the impairment of the rapid channel closing of Proteomonas sulcata anion channelrhodopsin 1 at high Cl- concentrations. Sci. Rep. 8, 13445 (2018).

33. Kushnirov, V. V. Rapid and reliable protein extraction from yeast. Yeast 16, 857860 (2000).

34. Maierhofer, T. et al. A Single-Pore Residue Renders the Arabidopsis Root Anion Channel SLAH2 Highly Nitrate Selective. Plant Cell 26, 2554-2567 (2014).

35. Brown, S. B. et al. New trends in photobiology biosynthesis of phycobilins. Formation of the chromophore of phytochrome, phycocyanin and phycoerythrin. J. Photochem. Photobiol. B 5, 3-23 (1990).

36. Faulkner, S. T. et al. Single-Cell and Bulk Fluorescence Excitation Signatures of Seven Phytoplankton Species During Nitrogen Depletion and Resupply. Appl. Spectrosc. 73, 304-312 (2019).

37. Marcus, Y. Ionic radii in aqueous solutions. Chem. Rev. 88, 1475-1498 (1988).

38. Li, H. et al. Crystal structure of a natural light-gated anion channelrhodopsin. Elife 8, 213 (2019).

39. Kim, Y. S. et al. Crystal structure of the natural anion-conducting channelrhodopsin GtACR1. Nature 561, 343-348 (2018).

40. Li, H. et al. The Crystal Structure of Bromide-Bound GtACR1 Reveals a PreActivated State. bioRxiv, doi: https://doi.org/10.1101/2020.12.31.424927. 
Tables

Table 1. Gene and amino acid information of ACRs used in this study.

\begin{tabular}{lllllc}
\hline $\begin{array}{l}\text { Protein name } \\
\text { abbreviation }\end{array}$ & Organism & Accession & $\begin{array}{l}\mathbf{6 8}^{\text {th }} \\
\text { residue in } \\
\text { GtACR1 }\end{array}$ & $\begin{array}{l}\mathbf{1 0 2}^{\text {th }} \\
\text { residue in } \\
\text { GtACR1 }\end{array}$ & $\begin{array}{l}\text { Number } \\
\text { of amino } \\
\text { acids }\end{array}$ \\
\hline GtACR1 & Guillardia & KP171708 & Glu & Cys & 295 \\
& theta & & & & \\
& CCMP2712 & & & & \\
\hline PsuACR1 & Proteomonas & KF992074 & Glu & Cys & 291 \\
ZipACR & sulcata & KX879679 & Glu & Cys & 314 \\
PsuACR_353 & CCMP704 & MG831189 & Glu & Thr & 303 \\
\hline GcACR_145 & Geminigera & KX879675 & Glu & Cys & 326 \\
GcACR_197 & cryophila & MG831184 & Glu & Val & 332 \\
GcACR_201 & CCMP2564 & MG831185 & Glu & Thr & 288 \\
GcACR_439 & & KX879676 & Glu & Cys & 340 \\
GcACR_457 & & KX879674 & Glu & Cys & 316 \\
\hline
\end{tabular}

Data taken from ${ }^{4,15-18}$.

Table 2. Summary of ionic and hydrated radii of anions tested in this study.

\begin{tabular}{lll}
\hline Anion & Ionic radius / nm & Hydrated radius / nm \\
\hline $\mathrm{F}^{-}$ & 0.124 & 0.263 \\
$\mathrm{Cl}^{-}$ & 0.180 & 0.319 \\
$\mathrm{Br}^{-}$ & 0.198 & 0.337 \\
$\mathrm{I}^{-}$ & 0.225 & 0.365 \\
$\mathrm{NO}_{3}{ }^{-}$mean & 0.177 & 0.316 \\
$\mathrm{NO}_{3}{ }^{-}$axial & - & 0.265 \\
$\mathrm{NO}_{3}{ }^{-}$equatorial & - & 0.345 \\
$\mathrm{SO}_{4}{ }^{2-}$ & 0.242 & 0.382 \\
\hline
\end{tabular}

Data taken from ${ }^{37}$. 


\section{Figure Legends}

Figure 1. Illustration of the concept of the $\mathrm{pH}$ electrode method for measuring anion transport activity of ACRs expressed in yeast P. pastoris cells. In this system, ACRs import anions according their electrochemical potential gradient because the anion concentration outside the cells was kept higher $(300 \mathrm{mM})$ than inside (nearly $0 \mathrm{mM}$ ). Therefore, a $\mathrm{pH}$ increase will be detected due to the secondary influx of protons to compensate the membrane potential being more negative due to the influx of anions.

Figure 2. Anion transport activity of GtACR1 measured using the $\mathrm{pH}$ electrode method. (a) Comparisons of $\mathrm{Cl}^{-}$transport activities in the absence (black line) or presence of 10 $\mu \mathrm{M}$ CCCP (red line); the negative control (grey line) was yeast cells without integration of the GtACR1 gene. $530 \mathrm{~nm}$ LED light $\left(10 \mathrm{~mW} / \mathrm{cm}^{2}\right)$ was illuminated for $2 \mathrm{~min}$ as shown on a white background. (b) The color of pigmented yeast cell suspension expressing GtACR1 changed from pink to yellow by adding $10 \mu \mathrm{M}$ CCCP, probably due to denaturation. (c) Comparisons of $\mathrm{Cl}^{-}$transport activities at various excitation light wavelengths $\left(10 \mathrm{~mW} / \mathrm{cm}^{2}\right)$. LED lights were illuminated for $2 \mathrm{~min}$ as shown on a white background. (d) Statistical comparisons of $\mathrm{Cl}^{-}$transport activities at various excitation light wavelengths. Data are reported as means and S.E.M.; the numbers in parentheses indicate the number of independent experiments. One-way ANOVA followed by Tukey's test was performed (p-value; ***<0.0006). (e) Visible absorption spectrum of purified GtACR1 suspended in $10 \mathrm{mM}$ MOPS ( $\mathrm{pH} 7$ ) buffer containing $1 \mathrm{M} \mathrm{NaCl}$ and $0.05 \% n$ Dodecyl- $\beta$-D-maltoside (DDM). (f) Comparisons of anion-dependent transport activities. $530 \mathrm{~nm}$ LED light $\left(10 \mathrm{~mW} / \mathrm{cm}^{2}\right)$ was illuminated for $2 \mathrm{~min}$ as shown on a white background. (g) Statistical comparisons of anion-dependent transport activities. Data are reported as means and S.E.M.; the numbers in parentheses indicate the number of independent experiments. One-way ANOVA followed by Dunnett's test was performed (p-values; $* * * *<0.0001, * * * 0.0001, * * 0.0084)$. The negative control was yeast cells without integration of the GtACR1 gene resuspended in $300 \mathrm{mM} \mathrm{NaCl}$.

Figure 3. ACRs tested using the $\mathrm{pH}$ electrode method. (a) Phylogenetic relationship of 45 ACRs analyzed by MEGA 7 software. According to amino acids conserved at position 102 in GtACR1, ACRs are classified into three types, Cys-type (blue), Thr-type (green) 
and Val-type (orange). (b) Pictures of pigmented yeast cells due to the functional expression of each ACR in the presence of all-trans-retinal. The negative control was yeast cells without integration of any ACR gene. (c) Comparisons of $\mathrm{Cl}^{-}$transport activities of ACRs. LED lights were illuminated for 2 or 3 min as shown on a white background.

Figure 4. Anion transport activity of PsuACR_353 measured using the $\mathrm{pH}$ electrode method. (a) Comparisons of $\mathrm{Cl}^{-}$transport activities at various excitation light wavelengths $\left(10 \mathrm{~mW} / \mathrm{cm}^{2}\right)$. LED lights were illuminated for $2 \mathrm{~min}$ as shown on a white background. (b) Statistical comparisons of $\mathrm{Cl}^{-}$transport activities at various excitation light wavelengths. Data are reported as means and S.E.M.; the numbers in parenthesis indicate the numbers of independent experiments. One-way ANOVA followed by Tukey's test was performed ( $p$-value; * 0.0471). (c) Comparisons of anion-dependent transport activities. $530 \mathrm{~nm}$ LED light $\left(10 \mathrm{~mW} / \mathrm{cm}^{2}\right)$ was illuminated for $2 \mathrm{~min}$ as shown on a white background. (d) Statistical comparisons of anion-dependent transport activities. Data are reported as means and S.E.M.; the numbers in parentheses indicate the number of independent experiments. One-way ANOVA followed by Dunnett's test was performed (p-values; $* * * * 0.0001, * * * 0.0002, * 0.0461)$. The negative control was yeast cells without integration of the PsuACR_353 gene resuspended in $300 \mathrm{mM} \mathrm{NaCl}$.

Figure 5. Quantitative comparisons of the anion transport activities of GtACR1, PsuACR_353 and their mutants. (a) Western blotting using anti-His-tag mAb after SDSPAGE; each ACR has monomer and dimer bands as indicated by filled and open triangles, respectively. The sum of band intensities was used to estimate protein expression levels. (b) Statistical comparisons of relative expression levels. Data are reported as means and S.E.M.; the numbers in parentheses indicate the number of independent experiments. One-way ANOVA followed by Dunnett's test was performed (p-values; $* * * *<0.0001$, * 0.0124). (c) Statistical comparisons of the transport activities of $\mathrm{Cl}^{-}$(left) and $\mathrm{NO}_{3}{ }^{-}$ (right). Data were corrected by the relative expression level and are reported as means and S.E.M.; the numbers in parentheses indicate the number of independent experiments. One-way ANOVA followed by Tukey's test was performed (p-values; **** $<0.0001$, $* * *<0.0007, * *<0.0049, *<0.0492)$. 
Figure 6. Anion transport activities of GtACR1-C102T and the PsuACR_353-T108C mutants. (a) Location of the Cys102 residue in the GtACR1 structure (PDB ID 6CSM) ${ }^{39}$. Cys102 and the all-trans-retinylidene chromophore are shown in stick representation by PyMOL. (b, d) Comparisons of anion-dependent transport activities of (b) GtACR1C102T and (d) PsuACR_353-T108C mutants. $530 \mathrm{~nm}$ LED light $\left(10 \mathrm{~mW} / \mathrm{cm}^{2}\right)$ was illuminated for 2 min as shown on a white background. (c, e) Statistical comparisons of anion-dependent transport activities of (c) GtACR1-C102T and (e) PsuACR_353-T108C mutants. Data are reported as means and S.E.M.; the numbers in parentheses indicate the number of independent experiments. One-way ANOVA followed by Dunnett's test was performed (p-values; for GtACR1-C102T ****<0.0001, * 0.0197; for PsuACR_353$\mathrm{T} 108 \mathrm{C} * * * *<0.0001, * * *<0.0007, * 0.0338)$. Negative controls are yeast cells without integration of any ACR gene resuspended in $300 \mathrm{mM} \mathrm{NaCl}$. 


\section{Figures}

\section{Figure 1.}

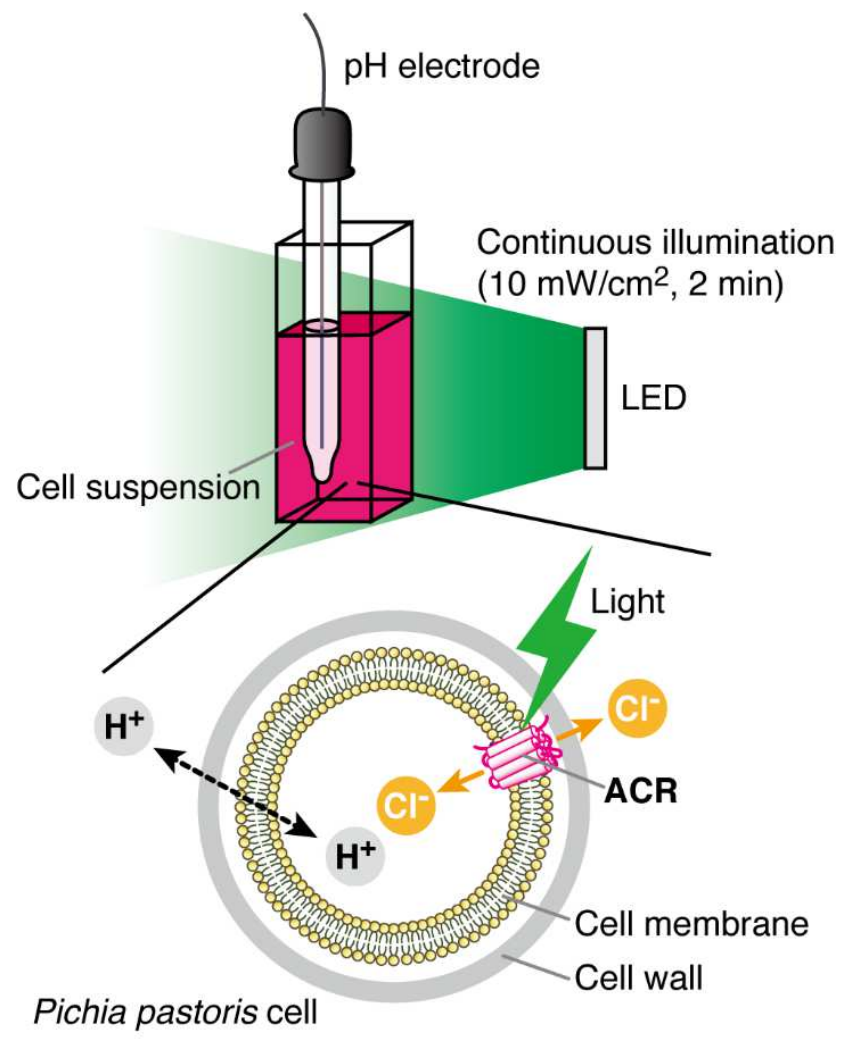




\section{Figure 2.}

(a)

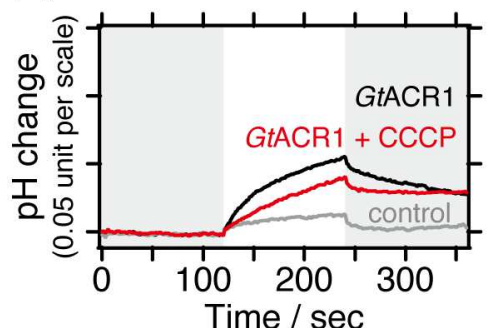

(c)
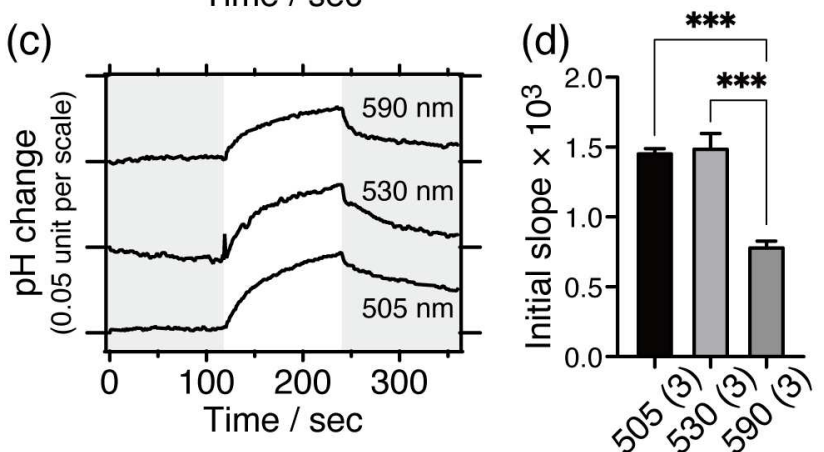

Wavelength / nm

(b)

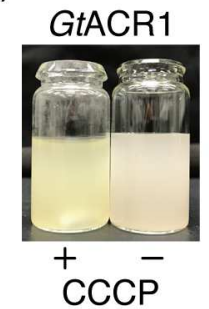

(e)

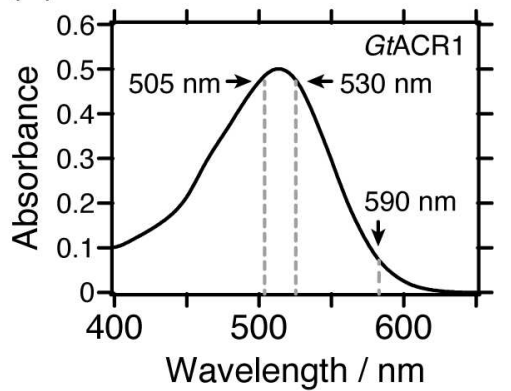

(f)

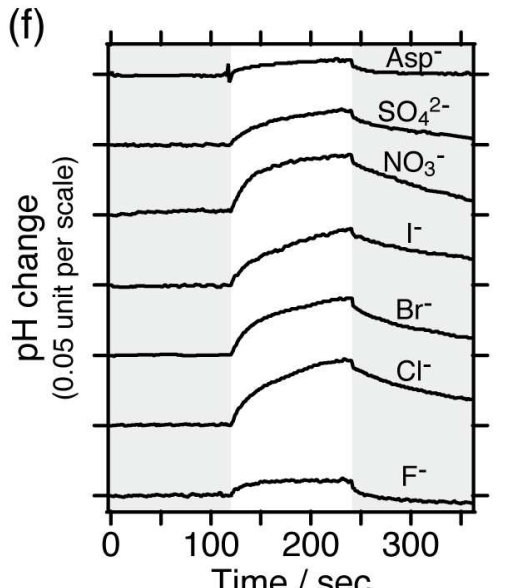

(g)

*****

$* * * *$

****

$* * * *$

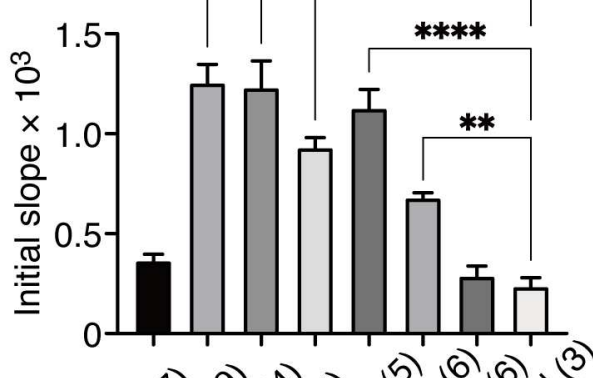

$<1$

(ब)

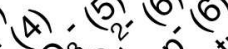

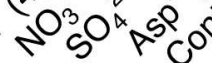

Anion (300 mM each) 


\section{Figure 3.}

(a) GcACR_439

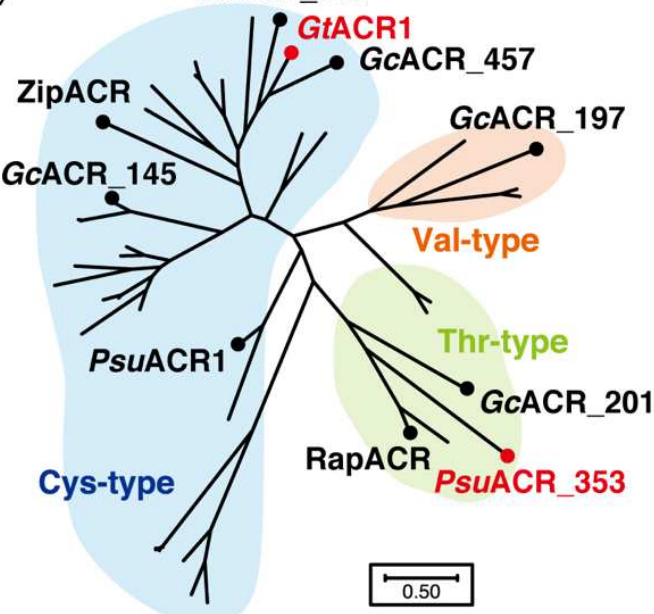

(b) P. pastoris

PsuACR1 (control) ZipACR PsuACR_353
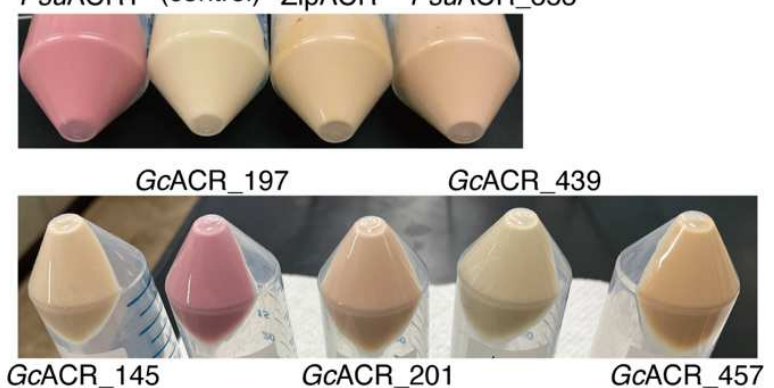

(c)

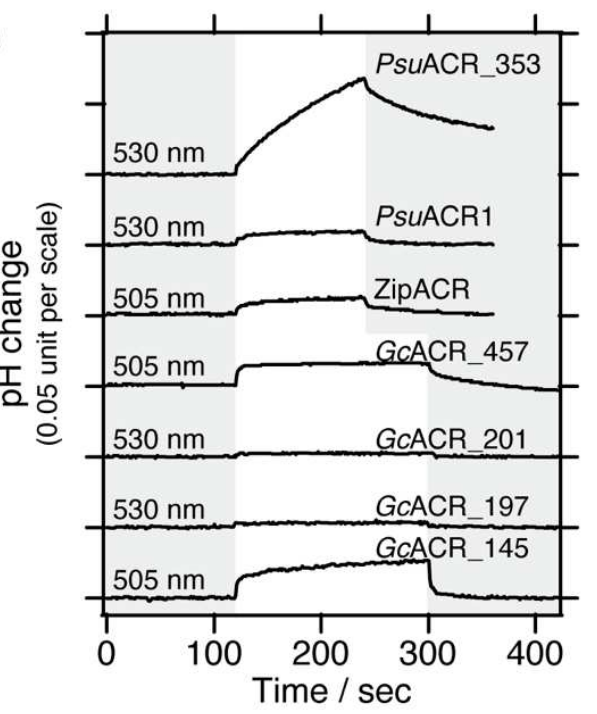




\section{Figure 4.}

(a)
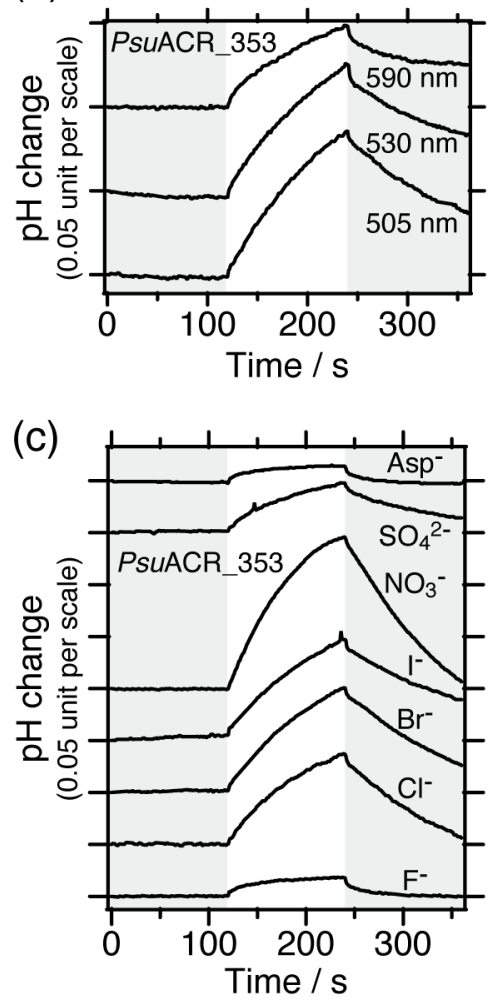

(b)

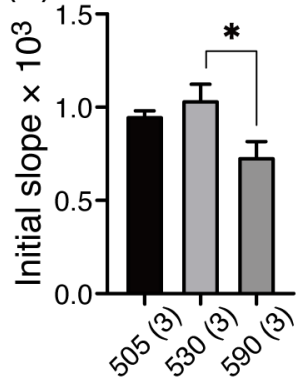

Wavelength / nm

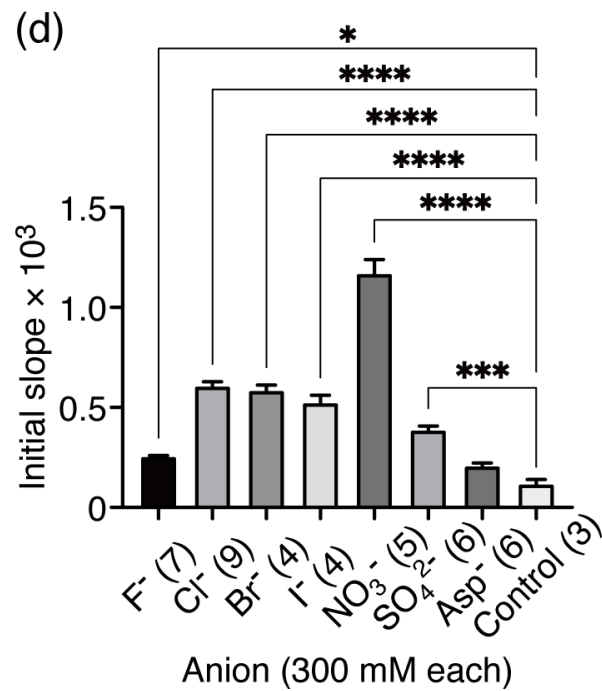




\section{Figure 5.}

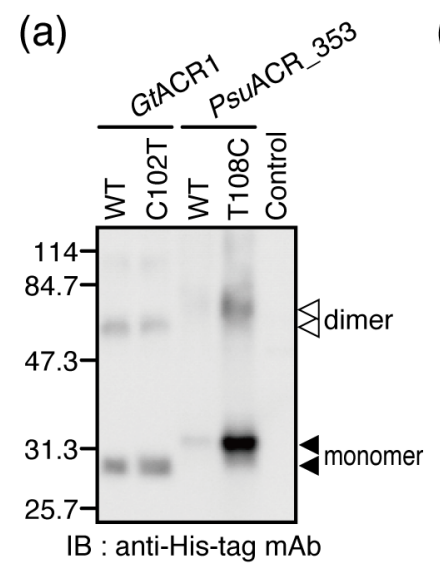

(b)

(c) $\mathrm{Cl}^{-} \quad \mathrm{NO}_{3}{ }^{-}$
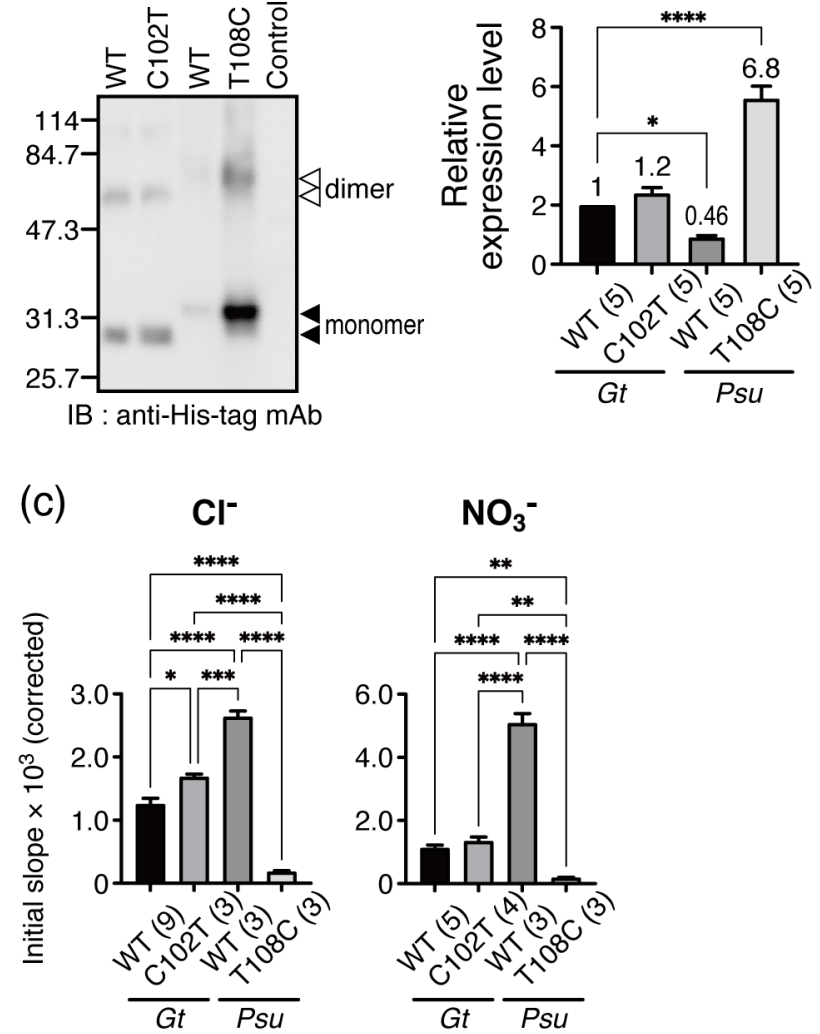
Figure 6.

(a)

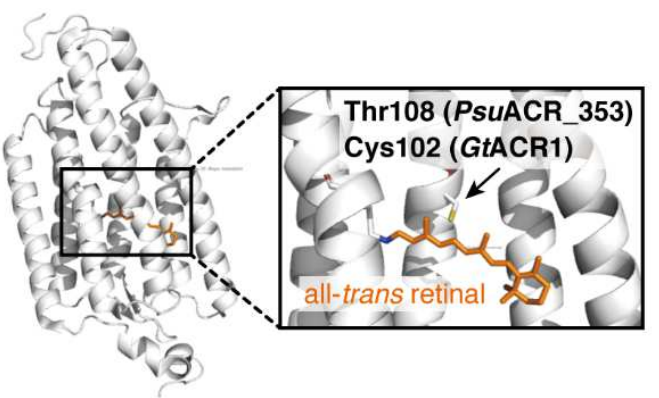

(b)

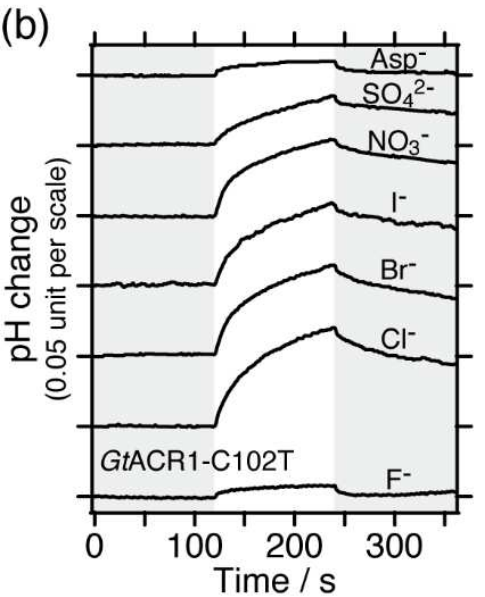

(d)

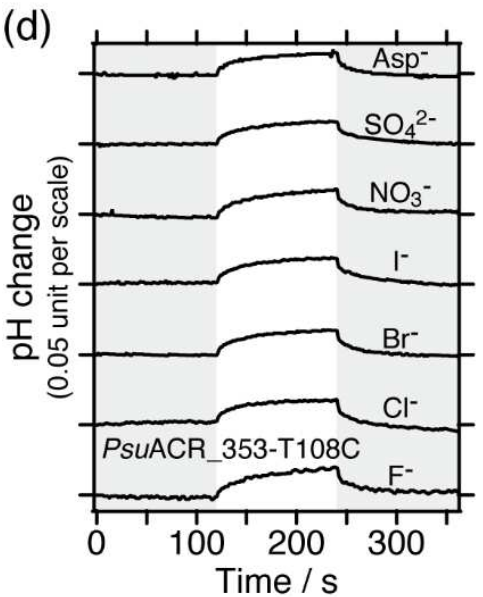

(c)

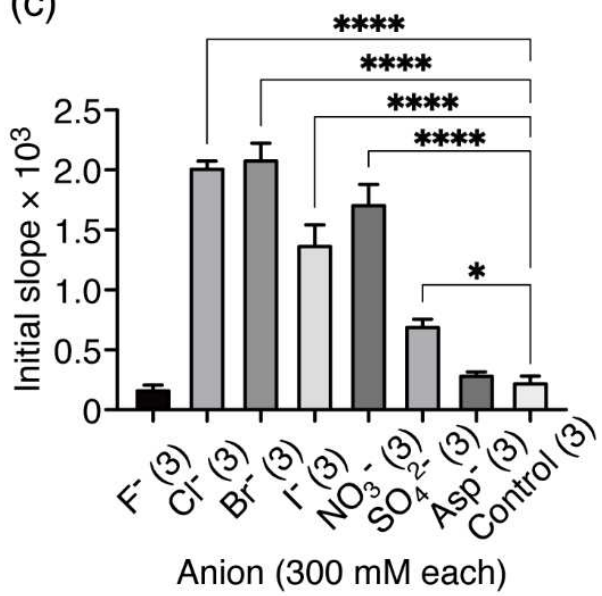

(e)

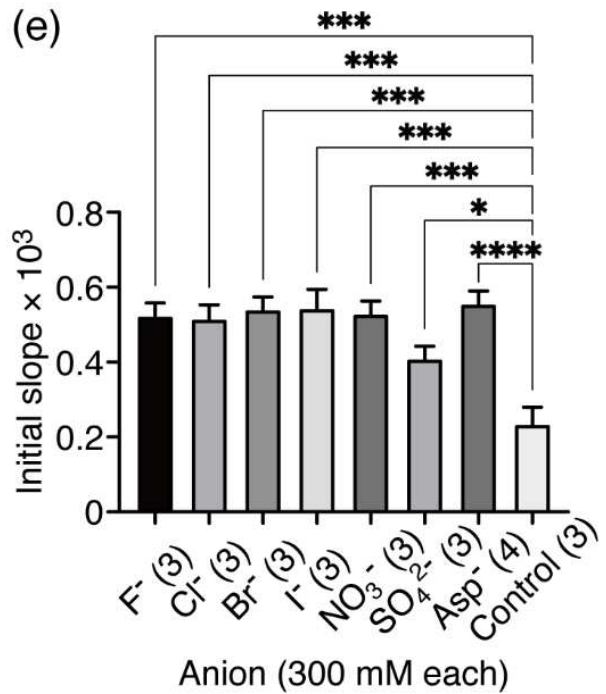




\section{Figures}

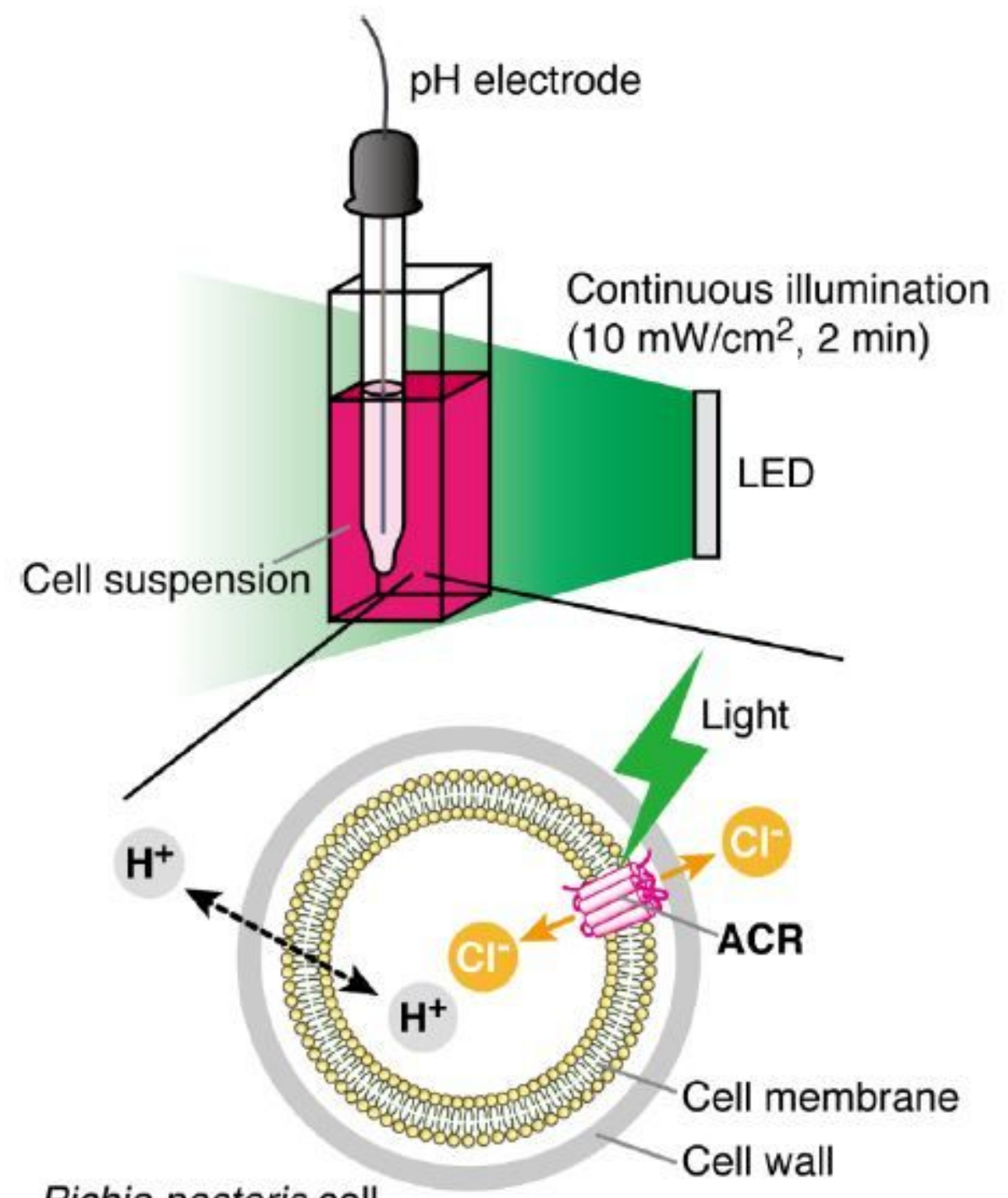

Pichia pastoris cell

\section{Figure 1}

Illustration of the concept of the $\mathrm{pH}$ electrode method for measuring anion transport activity of ACRs expressed in yeast P. pastoris cells. In this system, ACRs import anions according their electrochemical potential gradient because the anion concentration outside the cells was kept higher ( $300 \mathrm{mM})$ than inside (nearly $0 \mathrm{mM}$ ). Therefore, a pH increase will be detected due to the secondary influx of protons to compensate the membrane potential being more negative due to the influx of anions. 
(a)
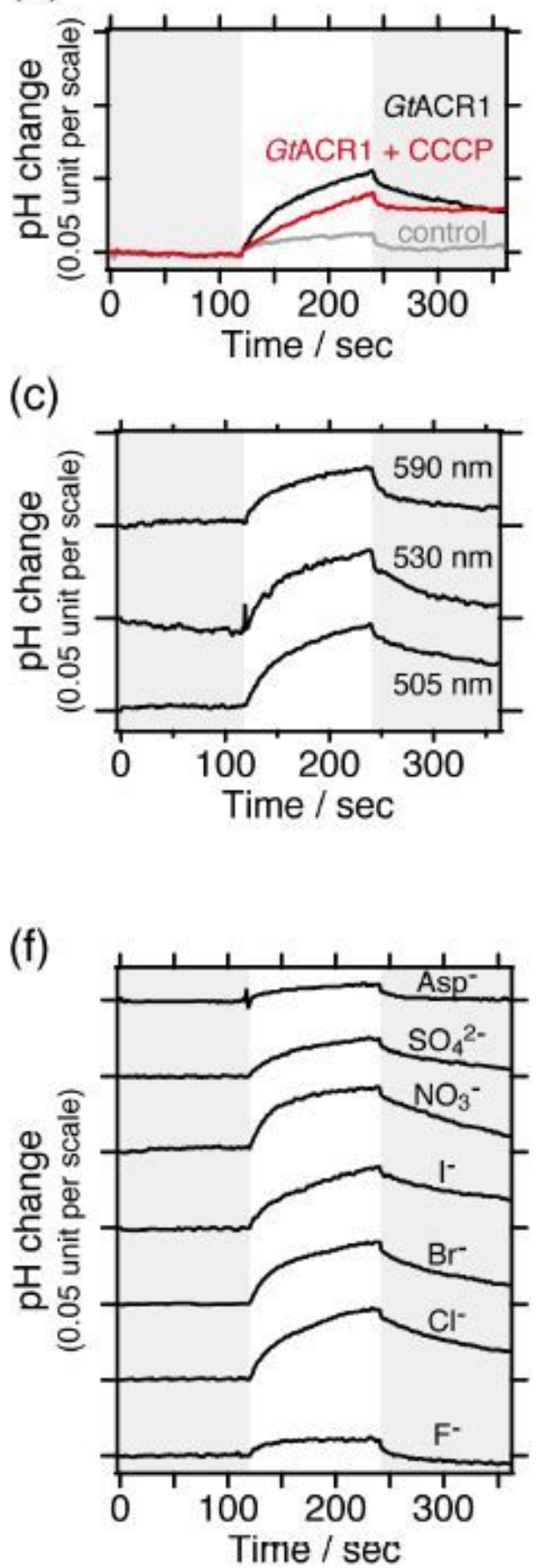

(b)
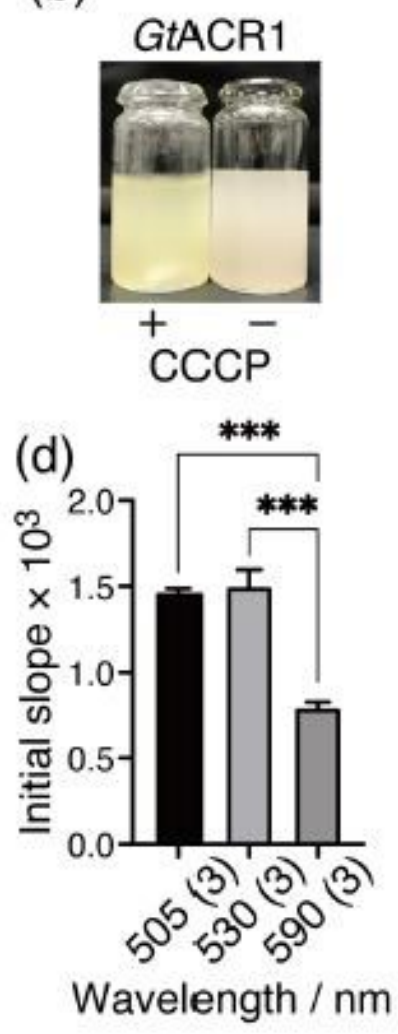

(e)

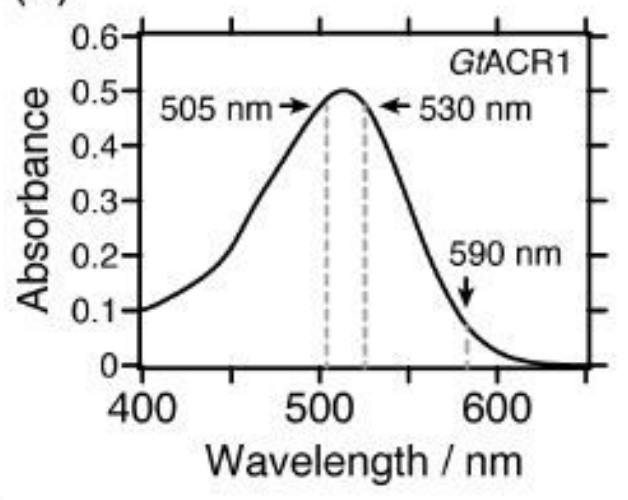

(g)

*****

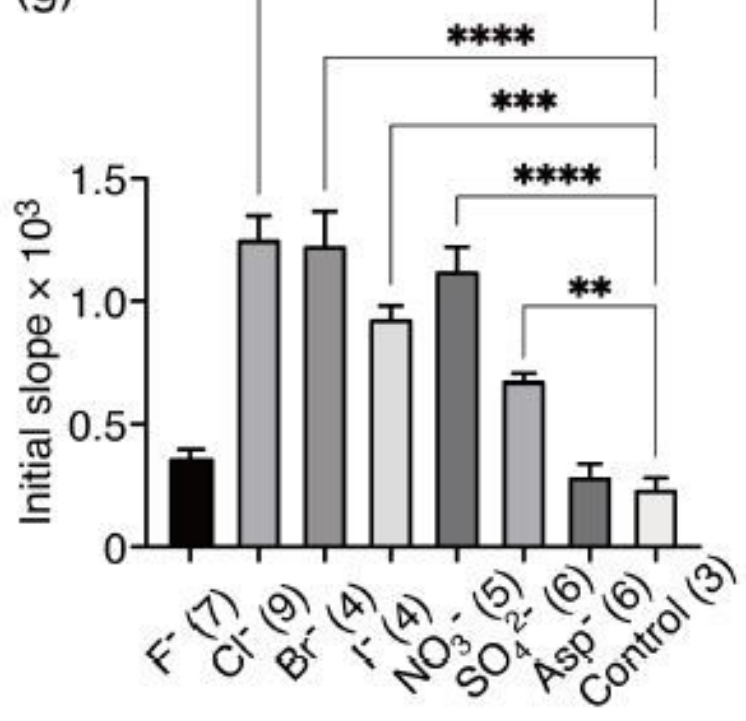

Anion (300 mM each)

\section{Figure 2}

Anion transport activity of GtACR1 measured using the pH electrode method. (a) Comparisons of Cltransport activities in the absence (black line) or presence of $10 \mu \mathrm{M} \mathrm{CCCP} \mathrm{(red} \mathrm{line);} \mathrm{the} \mathrm{negative} \mathrm{control}$ (grey line) was yeast cells without integration of the GtACR1 gene. $530 \mathrm{~nm}$ LED light $(10 \mathrm{~mW} / \mathrm{cm} 2)$ was illuminated for 2 min as shown on a white background. (b) The color of pigmented yeast cell suspension expressing GtACR 1 changed from pink to yellow by adding $10 \mu \mathrm{M} \mathrm{CCCP,} \mathrm{probably} \mathrm{due} \mathrm{to} \mathrm{denaturation.} \mathrm{(c)}$ 
Comparisons of $\mathrm{Cl}$ - transport activities at various excitation light wavelengths $(10 \mathrm{~mW} / \mathrm{cm} 2)$. LED lights were illuminated for 2 min as shown on a white background. (d) Statistical comparisons of $\mathrm{Cl}$ - transport activities at various excitation light wavelengths. Data are reported as means and S.E.M.; the numbers in parentheses indicate the number of independent experiments. One-way ANOVA followed by Tukey's test was performed ( $p$-value; $* \star *<0.0006)$. (e) Visible absorption spectrum of purified GtACR1 suspended in $10 \mathrm{mM}$ MOPS (pH 7) buffer containing $1 \mathrm{M} \mathrm{NaCl}$ and $0.05 \%$ n-Dodecyl- $\beta$-D-maltoside (DDM). (f) Comparisons of anion-dependent transport activities. $530 \mathrm{~nm}$ LED light $(10 \mathrm{~mW} / \mathrm{cm} 2)$ was illuminated for 2 min as shown on a white background. (g) Statistical comparisons of anion-dependent transport activities. Data are reported as means and S.E.M.; the numbers in parentheses indicate the number of independent experiments. One-way ANOVA followed by Dunnett's test was performed ( $p$-values; $* \star \star \star<~$ $0.0001, \star \star \star 0.0001, \star \star 0.0084)$. The negative control was yeast cells without integration of the GtACR1 gene resuspended in $300 \mathrm{mM} \mathrm{NaCl}$. 
(a)

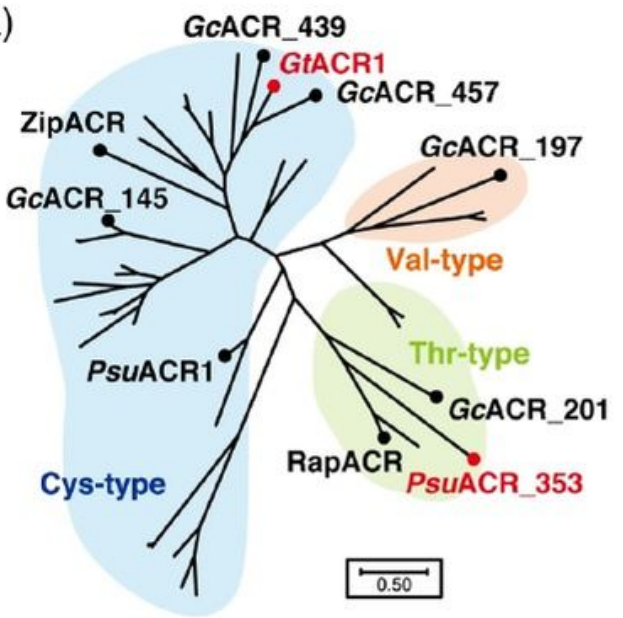

(b) P. pastoris

PsuACR1 (control) ZipACR PsuACR_353
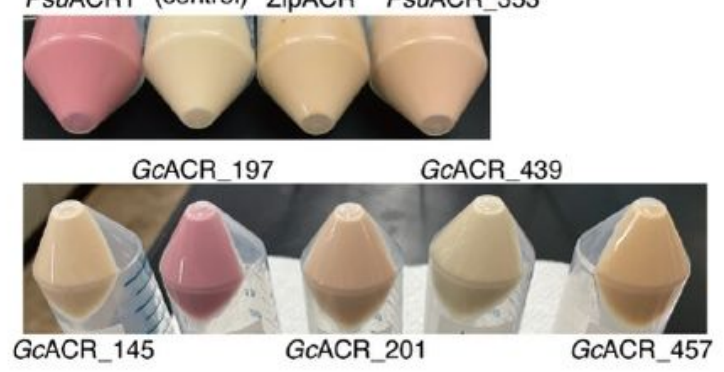

(c)

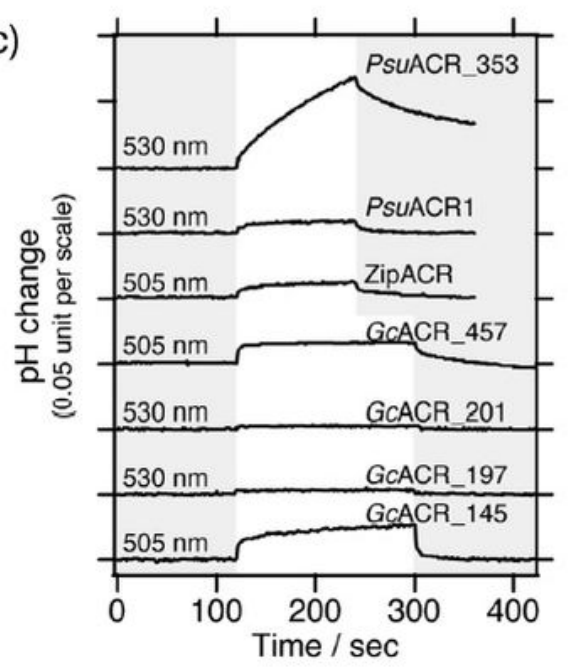

\section{Figure 3}

ACRs tested using the $\mathrm{pH}$ electrode method. (a) Phylogenetic relationship of 45 ACRs analyzed by MEGA 7 software. According to amino acids conserved at position 102 in GtACR1, ACRs are classified into three types, Cys-type (blue), Thr-type (green) and Val-type (orange). (b) Pictures of pigmented yeast cells due to the functional expression of each ACR in the presence of all-trans-retinal. The negative control was yeast 
cells without integration of any ACR gene. (c) Comparisons of $\mathrm{Cl}$ - transport activities of ACRs. LED lights were illuminated for 2 or 3 min as shown on a white background.

(a)
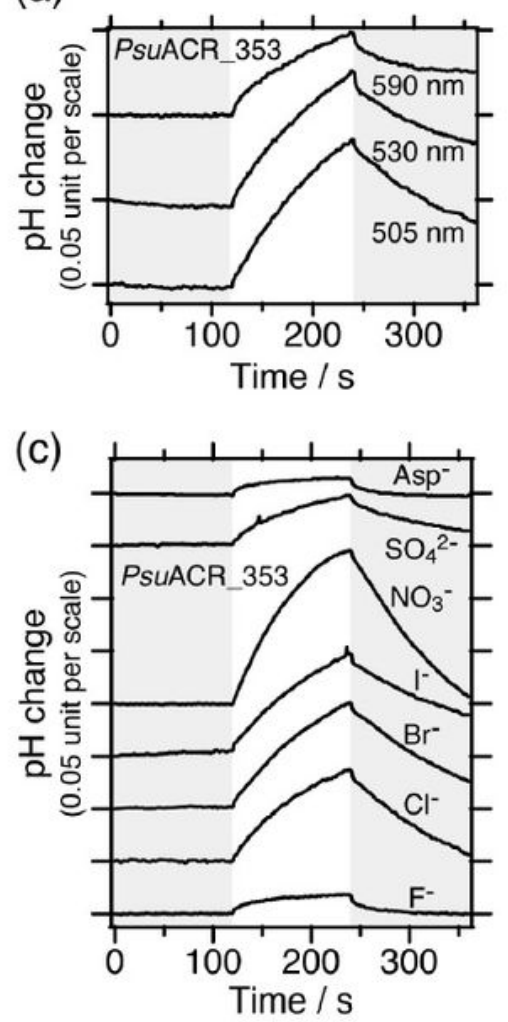

(b)

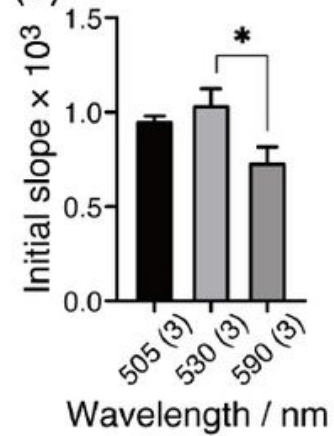

(d)

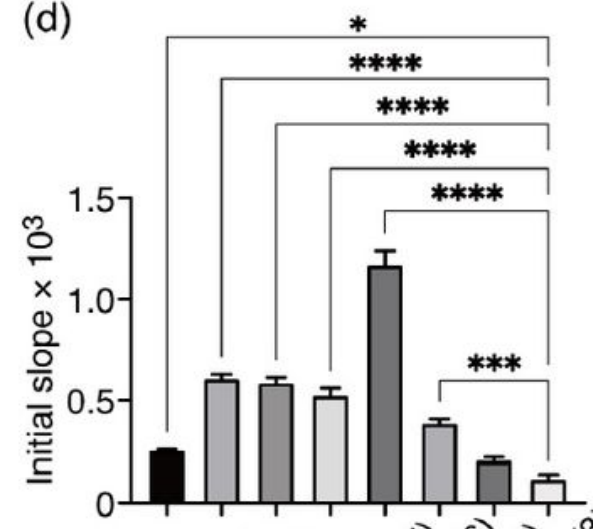

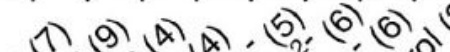

सc कि

Anion (300 mM each)

\section{Figure 4}

Anion transport activity of PsuACR_353 measured using the pH electrode method. (a) Comparisons of Cltransport activities at various excitation light wavelengths $(10 \mathrm{~mW} / \mathrm{cm} 2)$. LED lights were illuminated for 2 min as shown on a white background. (b) Statistical comparisons of $\mathrm{Cl}$ - transport activities at various 
excitation light wavelengths. Data are reported as means and S.E.M.; the numbers in parenthesis indicate the numbers of independent experiments. One-way ANOVA followed by Tukey's test was performed ( $p$ value; * 0.0471). (c) Comparisons of anion-dependent transport activities. $530 \mathrm{~nm}$ LED light (10 $\mathrm{mW} / \mathrm{cm} 2$ ) was illuminated for $2 \mathrm{~min}$ as shown on a white background. (d) Statistical comparisons of anion-dependent transport activities. Data are reported as means and S.E.M.; the numbers in parentheses indicate the number of independent experiments. One-way ANOVA followed by Dunnett's test was performed ( $p$-values; $\star \star \star \star<0.0001, \star \star \star 0.0002, * 0.0461$ ). The negative control was yeast cells without integration of the PsuACR_353 gene resuspended in $300 \mathrm{mM} \mathrm{NaCl}$. 


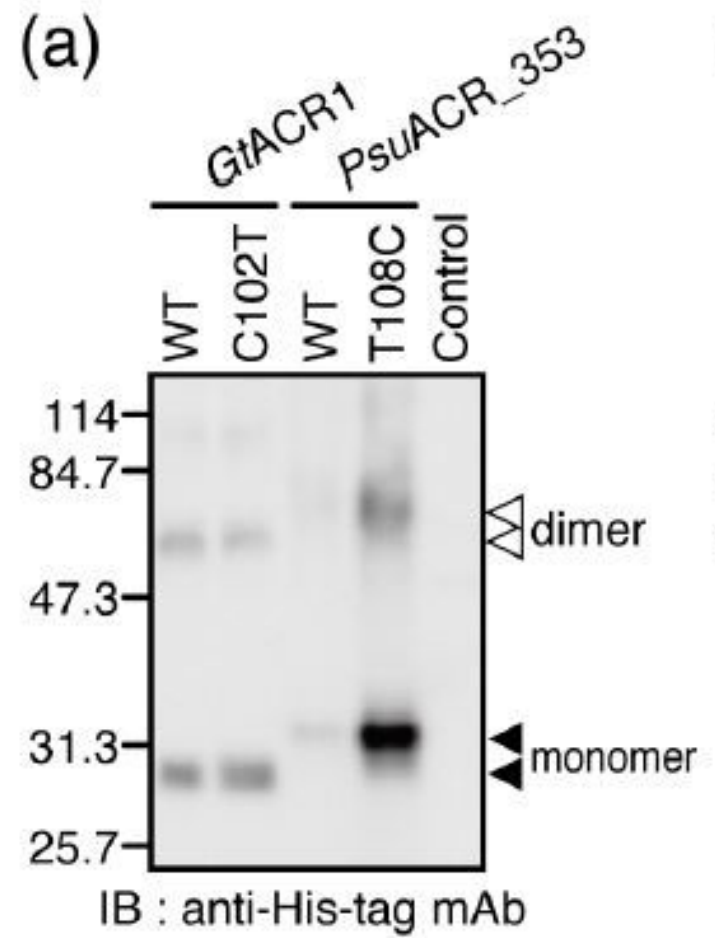

(b)
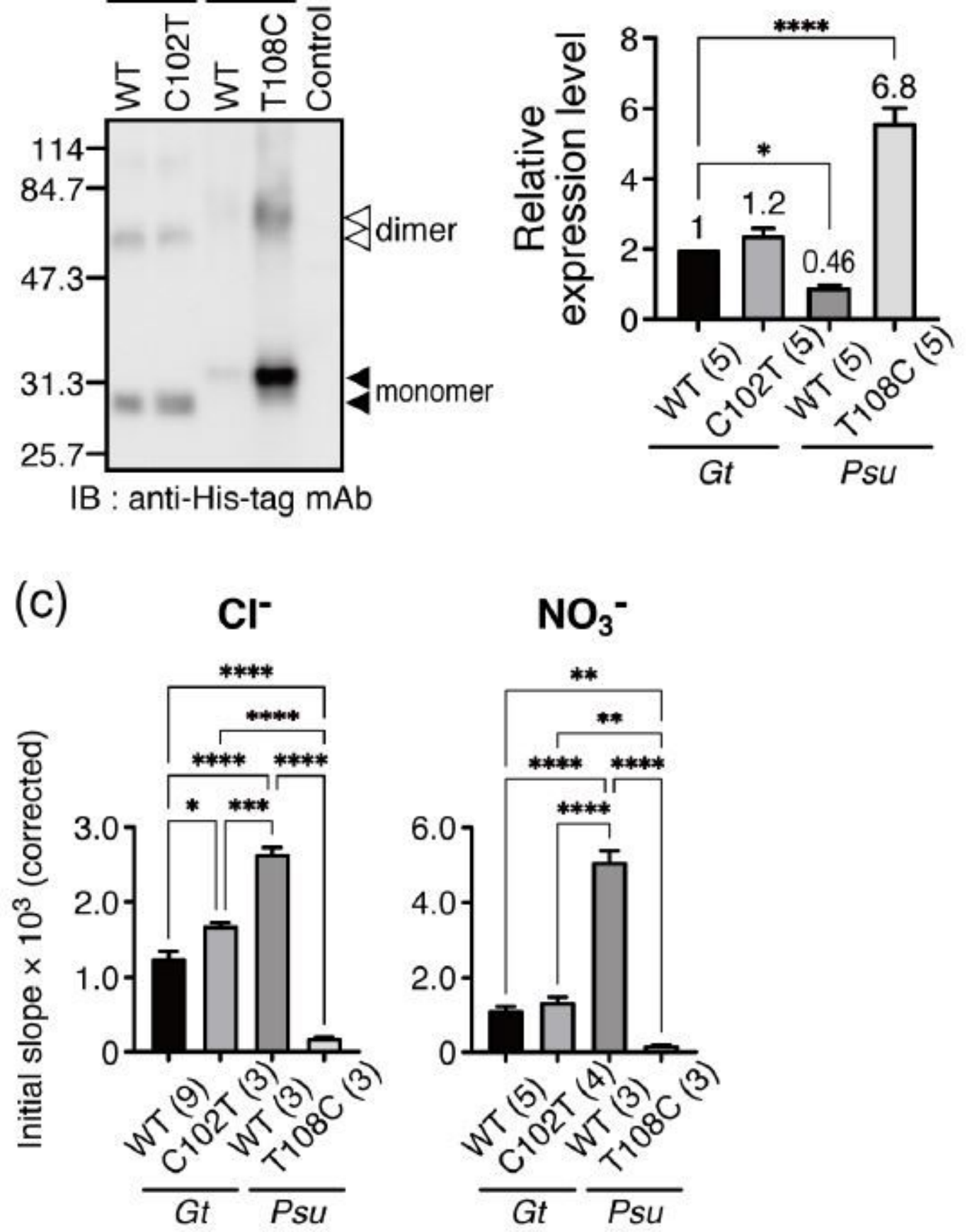

Figure 5

Quantitative comparisons of the anion transport activities of GtACR1, PsuACR_353 and their mutants. (a) Western blotting using anti-His-tag mAb after SDSPAGE; each ACR has monomer and dimer bands as indicated by filled and open triangles, respectively. The sum of band intensities was used to estimate protein expression levels. (b) Statistical comparisons of relative expression levels. Data are reported as means and S.E.M.; the numbers in parentheses indicate the number of independent experiments. One- 
way ANOVA followed by Dunnett's test was performed (p-values; $* \star \star \star<0.0001, * 0.0124$ ). (c) Statistical comparisons of the transport activities of $\mathrm{Cl}$ - (left) and NO3- (right). Data were corrected by the relative expression level and are reported as means and S.E.M.; the numbers in parentheses indicate the number of independent experiments. One-way ANOVA followed by Tukey's test was performed ( $p$-values; $* \star \star \star<~$ $0.0001, * * *<0.0007, * *<0.0049, *<0.0492)$.

(a)

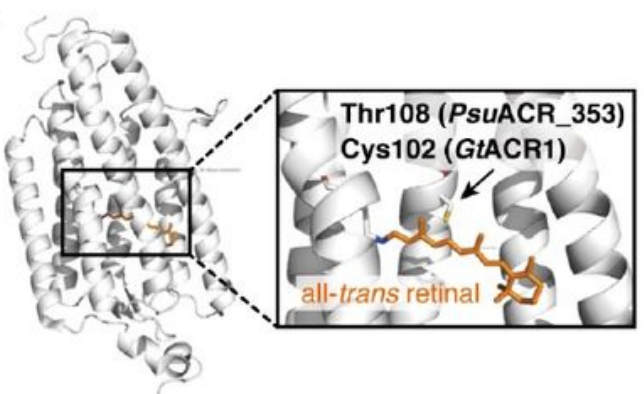

(b)

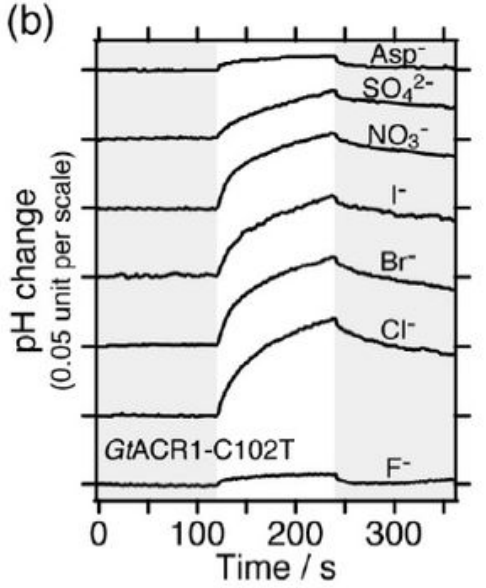

(d)

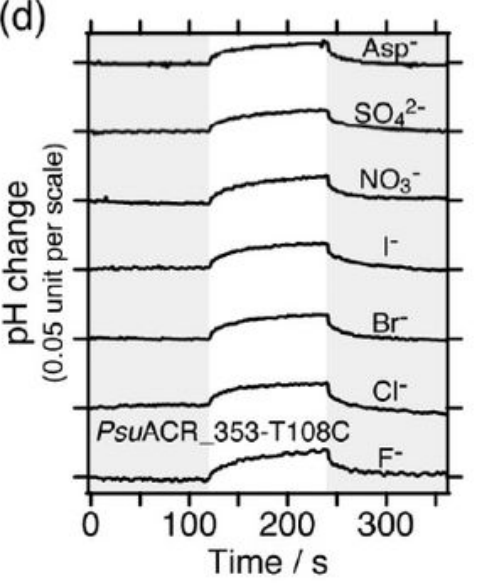

(c)

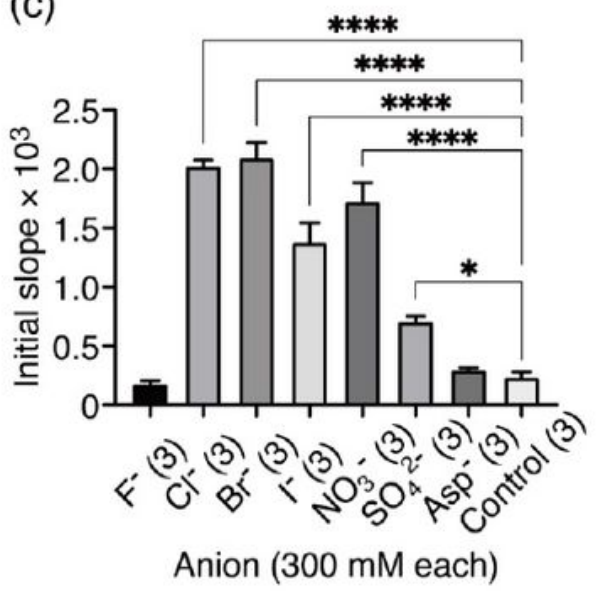

(e)

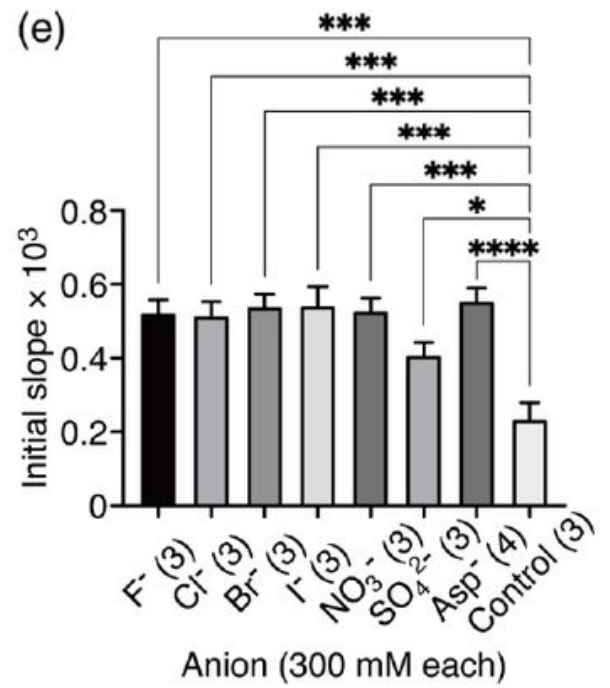

Figure 6 
Anion transport activities of GtACR1-C102T and the PsuACR_353-T108C mutants. (a) Location of the Cys102 residue in the GtACR1 structure (PDB ID 6CSM) 39. Cys102 and the all-trans-retinylidene chromophore are shown in stick representation by PyMOL. (b, d) Comparisons of anion-dependent transport activities of (b) GtACR1-C102T and (d) PsuACR_353-T108C mutants. $530 \mathrm{~nm}$ LED light (10 $\mathrm{mW} / \mathrm{cm} 2$ ) was illuminated for $2 \mathrm{~min}$ as shown on a white background. (c, e) Statistical comparisons of anion-dependent transport activities of (c) GtACR1-C102T and (e) PsuACR_353-T108C mutants. Data are reported as means and S.E.M.; the numbers in parentheses indicate the number of independent experiments. One-way ANOVA followed by Dunnett's test was performed ( $p$-values; for GtACR1-C102T

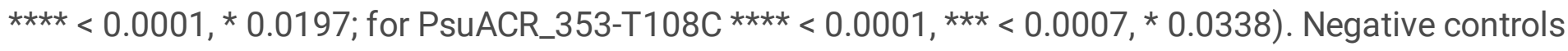
are yeast cells without integration of any ACR gene resuspended in $300 \mathrm{mM} \mathrm{NaCl}$.

\section{Supplementary Files}

This is a list of supplementary files associated with this preprint. Click to download.

- 210123SupplementaryInformation.pdf 